\title{
Disturbance Effect of Pipe Jacking Group Adjacent Excavation on Surrounding Soil
}

\author{
Changbai Wang $\mathbb{D}^{1,2}$ Jimin Liu $\mathbb{D}^{1,2}$ Hua Cheng $\mathbb{D}^{1,2,3}$ and Haibing Cai $\mathbb{C}^{1,2}$ \\ ${ }^{1}$ School of Civil Engineering and Architecture, Anhui University of Science and Technology, Huainan 232001, China \\ ${ }^{2}$ State Key Laboratory of Mining Response and Disaster Prevention and Control in Deep Coal Mine, \\ Anhui University of Science and Technology, Huainan, China \\ ${ }^{3}$ School of Resources and Environmental Engineering, Anhui University, Hefei 230601, China \\ Correspondence should be addressed to Jimin Liu; jimliu@aust.edu.cn
}

Received 19 February 2021; Revised 29 March 2021; Accepted 8 April 2021; Published 24 April 2021

Academic Editor: Chengwei Zhu

Copyright (c) 2021 Changbai Wang et al. This is an open access article distributed under the Creative Commons Attribution License, which permits unrestricted use, distribution, and reproduction in any medium, provided the original work is properly cited.

\begin{abstract}
Under the modern and complicated urban environment, clarifying the interaction mechanism and mutual influence mechanism between the urban tunnel and the surrounding environment is of considerable significance to the construction and operation of the tunnel. To understand and grasp the excavation-induced disturbance range and mechanism of adjacent pipeline jacking group on surrounding soils, this paper carries out relevant researches. Based on a case history of a three-hole parallel adjacent jacking pipeline in shallow overburden, a field test and assessment are performed. By setting monitoring points around the monitoring section, the earth pressure and water pressure under different buried depths and different spacing are monitored. For further discussion, the general law of soil disturbance around single-hole, double-hole, and three-hole jacking is investigated, the calculation method of lateral disturbance range and overlapping area range of pipe jacking group is deduced, and the degree of soil disturbance is evaluated as well. The results show that there will be different degrees of disturbance superposition in parallel multihole jacking due to the influence of the spacing, and the disturbance intensity is greatly affected by the parallel distance and buried depth.
\end{abstract}

\section{Introduction}

Pipe jacking technology is an underground pipeline construction method developed after shield tunnel. With its advantages of low comprehensive cost, high construction efficiency, and uninterrupted to urban traffic, it is widely used in municipal pipelines, underground pedestrian passageways, subways, and comprehensive pipe gallery. Due to the use of trenchless excavation technology, the surrounding soils are inevitably disturbed, which will lead to unloading or loading and other complex mechanical behaviors of the soil, resulting in changes in stress and strain of surrounding soils and even endangering the safety of adjacent buildings and underground pipelines, causing a series of environmental geotechnical problems. Therefore, the mechanism of soil disturbance caused by excavation has been the focus of scholars and engineering applications [1-4]. In recent years, with the need for urban underground space development, pipe jacking through existing subway tunnels, foundation pits, railway, and other adjacent projects is gradually increasing [5-10], which puts forward new requirements and research directions for soil disturbance mechanism of pipe jacking. And the disturbance effect of pipe jacking adjacent excavation on surrounding soil has gradually aroused attention.

Some theoretical research studies, field tests, and laboratory tests on soil disturbance caused by pipe jacking excavation have been conducted, and the corresponding evaluation methods and indicators have been studied as well. During pipe jacking excavation, due to the extrusion of jacking force, cutting shear force of the microtunnel boring machine (MTBM) head, and vibration load, the soils near 
the working face will have different degrees of disturbance in different areas. Fang et al. proposed the concept of soil disturbance zone division in pipe jacking construction [11]. Wei et al. expanded the soil disturbance zone to seven disturbance zones in combination with joint grouting and soil consolidation [12] and deduced the range of transverse and longitudinal disturbance zones caused by parallel pipe jacking [13]. Li and Miao studied the influence of grouting pressure and grouting amount on soil disturbance plastic zone based on the cavity expansion theory [14]. Chen et al. [15], Meng et al. [16], Xu et al. [17], and Lu et al. [18] had studied the evaluation index and method of disturbance based on laboratory tests. In the field test, according to the characteristics of the project, the field measurement, and analysis of the excavation disturbance of the surrounding soil of large-diameter circular pipe jacking $[19,20]$, rectangular pipe jacking [21], curved pipe jacking [22], and circular steel pipe jacking with flange plate [23] are carried out, and the relative research results are obtained.

Cavity expansion methods in geomechanics are a classic problem, which was widely used in stress-strain problems such as tunnel excavation, bolt support, shaft sinking, and in situ tests such as static CPT [24-27]. It is more significant that the cylindrical hole expansion theory under the isotropic initial stress state can also simulate the horizontal excavation construction process of urban underground pipeline and tunnel engineering, analyze the soil disturbance caused by horizontal excavation, and determine the maximum grouting pressure in the hole, which provides a practicable way for the research in this paper. Jia et al. [28] analyzed the expanded radius and internal expanding pressure of cylindrical hole and obtained the relationship between the plastic zone radius and the initial pore size and the expansion pressure based on the SMP criterion. With the help of FLAC numerical software, Han et al. [29] established a two-dimensional circular hole expansion model with pressure as the expansion boundary and analyzed the cavity shape and the distribution of the plastic zone.

At present, the research studies on soil disturbance mechanism mainly focus on single pipe jacking or parallel pipe jacking. The research on soil disturbance mechanism and field measurement of adjacent pipe jacking group is scarce. When there are more than two pipes excavating in sequence, what kind of disturbance effect will happen, whether there will be disturbance overlapping, and what is the relationship between the disturbance intensity and the center spacing of pipeline group and buried depth. These are the topics worthy of further study and discussion. Different from the previous researches, the disturbance effect of pipe jacking group adjacent excavation on surrounding soil would pay more attention to the soil disturbance perpendicular to the jacking direction, so the transverse disturbance range of soil will be focused on. Taking a practical three-hole parallel adjacent jacking in the drainage project of Meilan International Airport in Haikou as the engineering background, the disturbance effect of pipe jacking group adjacent excavation on surrounding soil is investigated, which would provide an engineering reference for similar projects.

\section{Determination of Lateral Disturbance Range of Pipe Jacking Group Adjacent Excavation}

For the convenience of the problem analysis, we make the following assumptions: (1) the material and section specification of the pipeline segment in the pipe jacking group are identical; (2) the jacking pipes of each hole are excavated in sequence, and the jacking speed is suitable and consistent; (3) the soil is homogeneous isotropic elastic-plastic cohesionless material, and the soil obeys the Mohr-Coulomb yield criterion. And the lateral disturbance range of single-hole excavation, double-hole excavation, three-hole excavation will be analyzed separately.

\subsection{The Lateral Disturbance Range of Single-Hole Excavation.} During single-hole pipe jacking, friction resistance is generated between the shell of MTBM and the surrounding soil, which makes the soil around the shell shear disturbance. At the same time, the horizontal excavation of pipe jacking will cause shear disturbance on the soil in the front of MTBM and excavation unloading on the soil upper front MTBM. Therefore, the horizontal excavation of single-hole pipe jacking will produce soil disturbance in a certain range perpendicular to the jacking direction.

Based on the field measurement and the theory of small hole expansion, the calculation method of the radius of plastic shear disturbance zone is given in the literature [30-34], but it is not suitable for shallow overburden engineering. Therefore, the shell shear disturbance zone will be further analyzed based on cavity expansion methods. And the pipe jacking in shallow overburden is regarded as cylindrical hole expansion in finite medium. The mechanical model is shown in Figure 1.

Referring to $a_{0}$ as the initial radius, the hole radius after expansion is called the expanding radiusa. Referring to $p_{0}$ as the initial pressure of the hole, $p$ is called the expansion pressure of the hole. When the uniformly distributed internal pressure changes from $p_{0}$ to $p$, the radius of the hole changes from $a_{0}$ to $a$. With the continuous increase of internal pressure, the soil around the hole begins to yield, from the original overall elastic state to the state containing both elastic and plastic regions. Therefore, the soil will be disturbed within the radius of plastic zone $r_{p}$, which is the radius of the shell shear disturbance zone $R^{\prime}$.

The soils around the cylindrical hole satisfy the differential equation of stress balance according to the cavity expansion method:

$$
\frac{\partial \sigma_{r}}{\partial r}+\frac{\sigma_{r}-\sigma_{\theta}}{r}=0
$$

where $\sigma_{r}$ and $\sigma_{\theta}$ are the radial and circumferential normal stresses, respectively, and $r$ is the polar radius.

The geometric and physical equations in the elastic region can be expressed as 


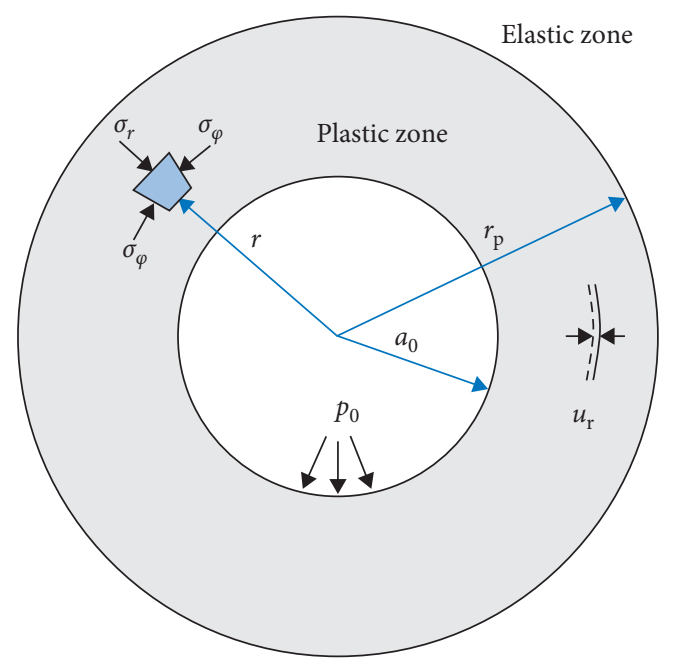

Figure 1: Mechanical model of cylindrical hole expansion.

$$
\begin{aligned}
& \left\{\begin{array}{l}
\varepsilon_{r}=-\frac{d u_{r}}{d_{r}}, \\
\varepsilon_{\theta}=-\frac{u_{r}}{r},
\end{array}\right. \\
& \left\{\begin{array}{l}
\varepsilon_{r}=\frac{1-v^{2}}{E}\left(\sigma_{r}-\frac{v}{1-\nu} \sigma_{\theta}\right), \\
\varepsilon_{\theta}=\frac{1-v^{2}}{E}\left(\sigma_{\theta}-\frac{v}{1-\nu} \sigma_{r}\right),
\end{array}\right.
\end{aligned}
$$

where $\varepsilon_{r}$ and $\varepsilon_{\theta}$ are the radial and circumferential strain, respectively, $E$ is the elastic modulus, and $\nu$ is Poisson's ratio.

Combining equations (1)-(3), the stress and displacement field of soils in elastic zone satisfy the following:

$$
\left\{\begin{array}{l}
\sigma_{r}=p_{0}+\left(p_{y}-p_{0}\right)\left(\frac{r_{p}}{r}\right)^{2}, \\
\sigma_{\theta}=p_{0}-\left(p_{y}-p_{0}\right)\left(\frac{r_{p}}{r}\right)^{2}, \\
u_{r}=\frac{p_{y}-p_{0}}{2 G}\left(\frac{r_{p}}{r}\right)^{2} r
\end{array}\right.
$$

where $G$ is the shear modulus of soil and $p_{y}$ is the expanding pressure at elastoplastic interface.

According to the basic assumption 3, the soil outside the hole obeys the Mohr-Coulomb criterion without considering the cohesion, and its yield criterion can be expressed as

$$
\frac{\sigma_{r}}{\sigma_{\theta}}=R_{p s}=\frac{1+\sin \varphi}{1-\sin \varphi}
$$

where $\varphi$ is the internal friction angle of soil, $R_{p s}$ is the ratio of large principal stress to small principal stress, and it is also the ratio of radial force to circumferential force.
The stress in the plastic zone satisfies both the differential equation of stress equilibrium and the Mohr-Coulomb criterion. Substituting equation (6) into equation (1), we get

$$
\sigma_{r}=A\left(\frac{1}{r}\right)^{1-\left(1 / R_{p s}\right)},
$$

where $A$ is the integral constant.

In the meanwhile, the soil in elastic zone also satisfies the Mohr-Coulomb criterion, by substituting the yield condition (6) into the stress field equation (4), the expansion pressure of the cylindrical hole at the beginning of yielding can be obtained, and it is also the radial stress at the radius of the plastic zone:

$$
p_{y}=\left.\sigma_{r}\right|_{r=r_{p}}=\frac{2 R_{p s} p_{0}}{1+R_{p s}} .
$$

The integral constant $A$ can be obtained by simultaneous equations (7) and (8):

$$
A=\frac{2 R_{p s} p_{0}}{1+R_{p s}} r_{p}^{1-\left(1 / R_{p s}\right)} .
$$

Then, the radial stress in the plastic zone is

$$
\sigma_{r}=\frac{2 R_{p s} p_{0}}{1+R_{p s}}\left(\frac{r_{p}}{r}\right)^{1-\left(1 / R_{p s}\right)},
$$

and the radius of the shell shear disturbance zone is

$$
r_{p}=\left(\frac{1+R_{p s}}{2 R_{p s} p_{0}}\right)^{R_{p s} /\left(R_{p s}-1\right)} a p^{R_{p s} /\left(R_{p s}-1\right)} .
$$

Therefore, the radius of the shell shear disturbance zone is

$$
R^{\prime}=r_{p}=\left(\frac{1+R_{p s}}{2 R_{p s} p_{0}}\right)^{R_{p s} /\left(R_{p s}-1\right)} a p^{R_{p s} /\left(R_{p s}-1\right)} .
$$

As jacking excavation, soil output, driving machine jacking, and other processes, the pipe jacking excavation will continue to disturb the surrounding soil along a certain angle to the ground. The complete boundary line on both sides will form a junction with the ground; thus, a lateral disturbance area forms, which is shown in Figure 2.

According to the limit equilibrium principle, the boundary of the disturbance zone should be tangent to the shear disturbance zone, and the horizontal elevation angle of the boundary line is equal to the active earth pressure angle

$$
\alpha=45^{\circ}+\frac{\varphi}{2}
$$

where $\varphi$ is the internal friction angle of the soil.

Therefore, the range of horizontal disturbance caused by single-hole pipe jacking is

$$
L=2 h \operatorname{tg}\left(45^{\circ}-\frac{\varphi}{2}\right)+2 \frac{R^{\prime}}{\cos \left(45^{\circ}-(\varphi / 2)\right)},
$$




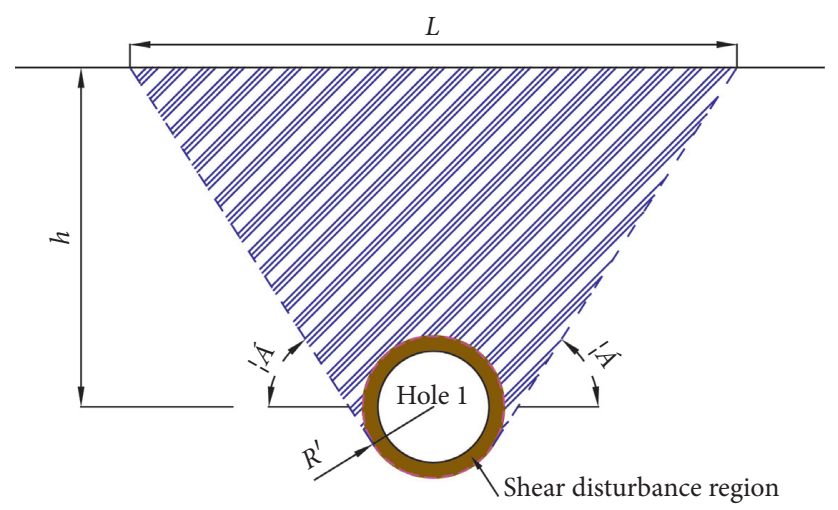

FIGURE 2: Schematic diagram of lateral disturbance range of single-hole jacking.

where $h$ is the vertical distance between the center of pipe segment and ground surface, $\varphi$ is the internal friction angle of soil, and $R^{\prime}$ is the radius of the shell shear disturbance zone, which can be determined by formula (12).

\subsection{The Lateral Disturbance Range of Double-Hole Excavation} and Disturbance Superposition. When the second jacking pipe excavates in sequence, the double-hole jacking pipeline will be formed. At this time, the influence of horizontal center spacing should be considered. If the center spacing between two holes is large, the second hole only produces soil disturbance near itself, and its lateral disturbance range is the same as that of single-hole jacking. If the center spacing between two holes is small, disturbance superposition will occur near the junction center of the two holes. Assuming that the center spacing of pipeline is $\mathrm{B}$, it satisfies

$$
B>2 h \operatorname{ctg} \alpha+\frac{2 R^{\prime}}{\sin \alpha} \text {. }
$$

The lateral disturbance range of the double hole is shown in Figure 3(a). The center spacing of the double hole is small and satisfies

$$
B<2 h \operatorname{ctg} \alpha+\frac{2 R^{\prime}}{\sin \alpha}
$$

The lateral disturbance range of the double hole is shown in Figure 3(b). And the lateral overlapping area range is

$$
L^{\prime}=2 h \operatorname{ctg} \alpha-B+\frac{2 R^{\prime}}{\sin \alpha} \text {. }
$$

2.3. The Lateral Disturbance Range of Three-Hole Excavation and Disturbance Superposition. When the third hole excavates in parallel, the influence of the lateral disturbance range is the same as that of double-hole jacking, but the jacking position of the third hole should be considered. If the third hole is jacked outside the previous two holes, it is consistent with the superposition effect of double-hole jacking, as shown in Figures 4(a) and 4(b). If the third hole is jacked in the middle of the previous two holes, it will be further overlapped in the previous two-hole overlapped area, as shown in Figures 4(c) and 4(d). The lateral disturbance zone of the third hole jacking and the lateral overlapping area range are the same as formulas (14) and (17).

\section{Case Description}

3.1. Overview. To effectively discharge the rainy season precipitation and municipal sewage around Meilan International Airport and the surrounding areas in Haikou, the construction method combining large-diameter adjacent pipe jacking group underground excavation with large-diameter box culvert open excavation is adopted. This project locates outside the red line of Meilan Airport phase II expansion project and passes through the nursery, industrial plants, and urban roads. The aerial view of the project is shown in Figure 5. Among them, a three-hole parallel jacking pipeline group is adopted in the area from No. 4 shaft to No. 5 shaft. The total length of pipe jacking group is 1470 meters, the horizontal center spacing of the pipe jacking group is 3.18 meters, and the average cover depth of the pipe section is about 3.93 meters. It started in October 2019 and finished in April 2020. The construction of No. 1 hole, No. 3 hole, and No. 2 hole has been carried out successively and the cross section of the pipe jacking group is the same, which is shown in Figure 6.

Each ring of the jacking pipeline adopts circular prefabricated reinforced concrete segments with a width of $0.32 \mathrm{~m}$. The inner diameter of the segment is $3.5 \mathrm{~m}$ and the length is $2.5 \mathrm{~m}$. To effectively bore through the soft soil layer, the MTBM is used in this project, whose whole length is $5.71 \mathrm{~m}$ and the outer shell diameter is $4.16 \mathrm{~m}$. In the meanwhile, the grouting system of synchronous grouting at the head and follow-up grouting at the pipe is adopted to ensure the jacking quality.

3.2. Geological Conditions. The strata at the construction site can be divided into three main layers and the soft subsoil is about $13.5 \mathrm{~m}$ thick. The water table is located at a depth of $2.3 \mathrm{~m}$ below the ground. The basic physical parameters and depth for these soils are given in Table 1. Plain fill (layer (1)) is located on the surface, and the silty clay (layer (2)) and coarse sand (layer (3) are underneath, respectively. The main strata of pipe jacking are silty clay and coarse sand. 


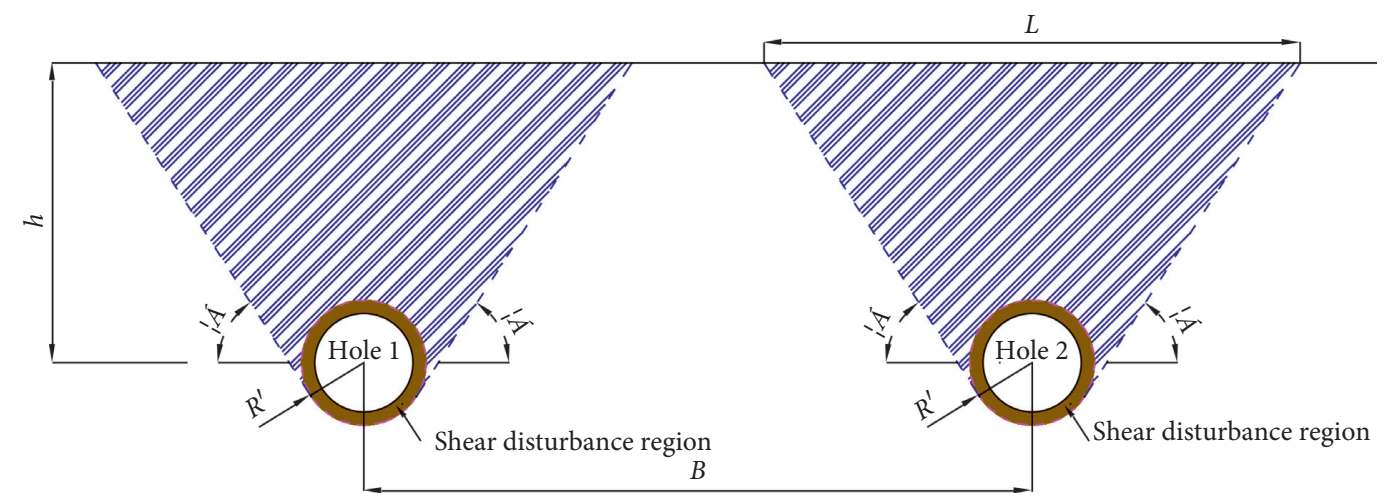

(a)

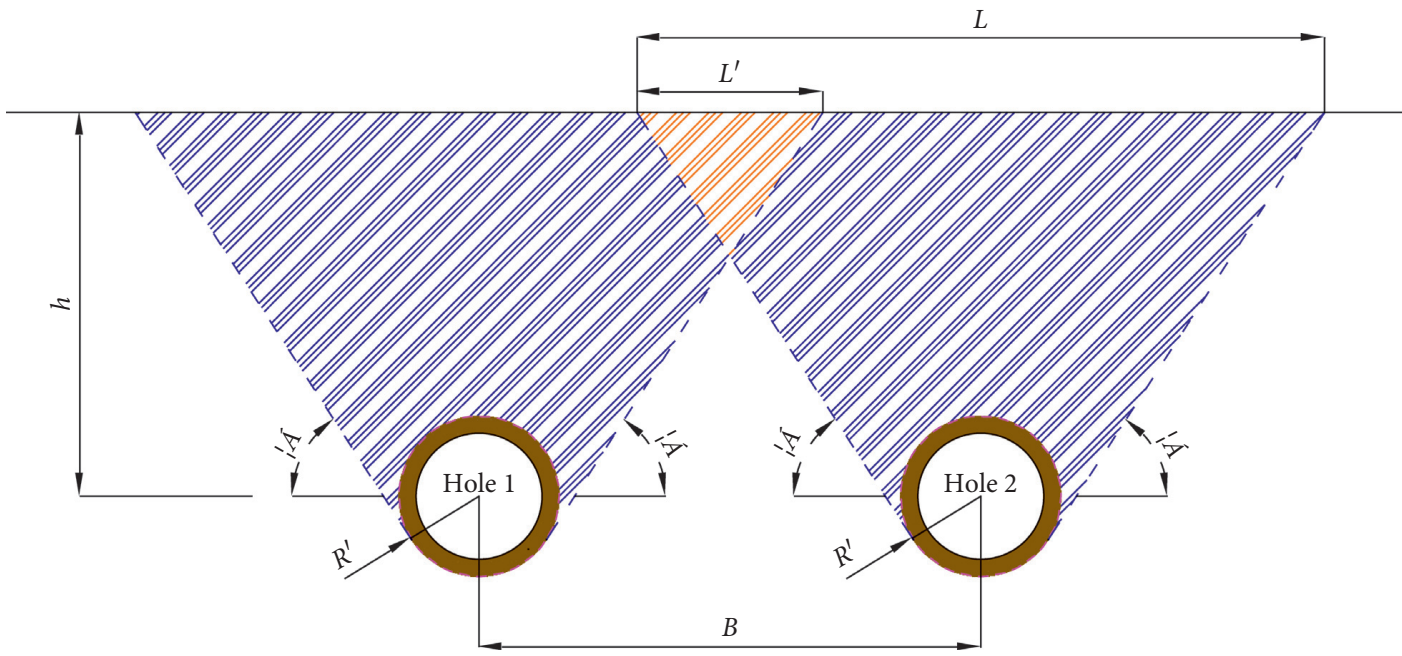

(b)

FiguRE 3: Schematic diagram of lateral disturbance range of double-hole jacking. (a) The center spacing is large in double-hole excavation. (b) The center spacing is small in double-hole excavation.

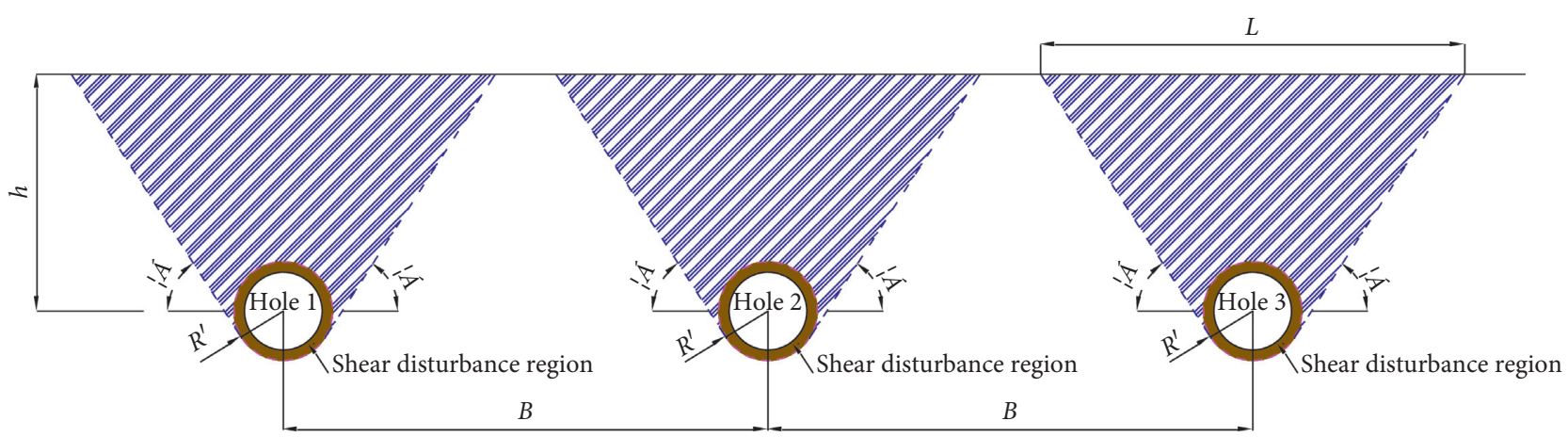

(a)

Figure 4: Continued. 


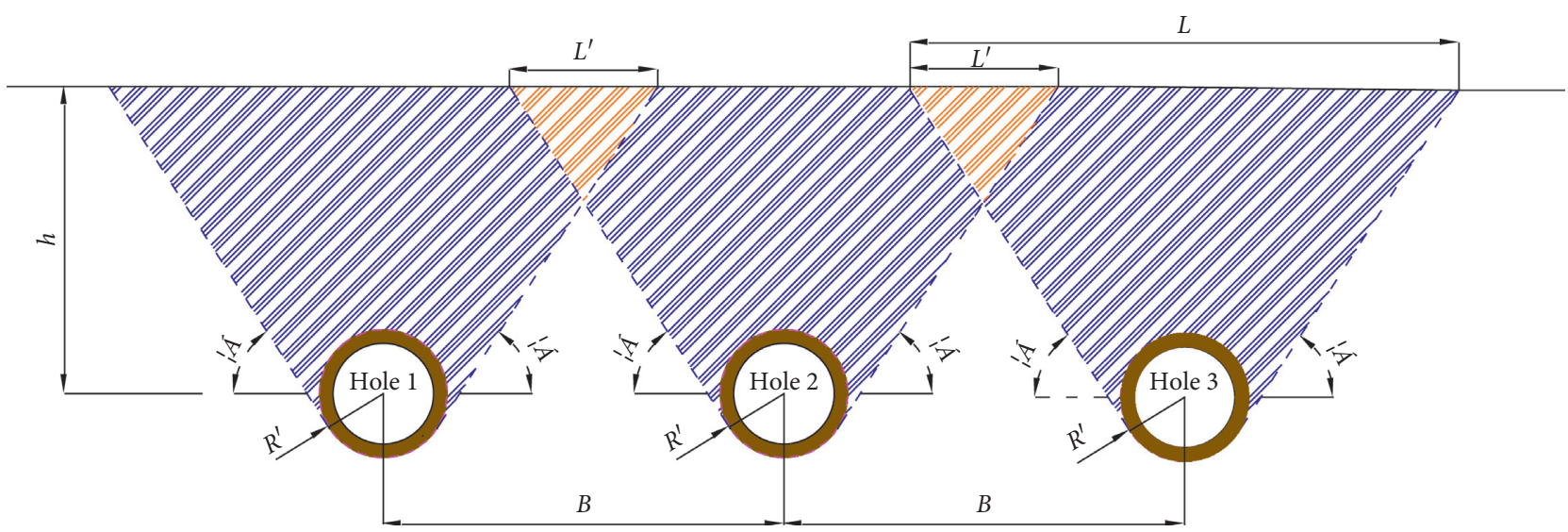

(b)

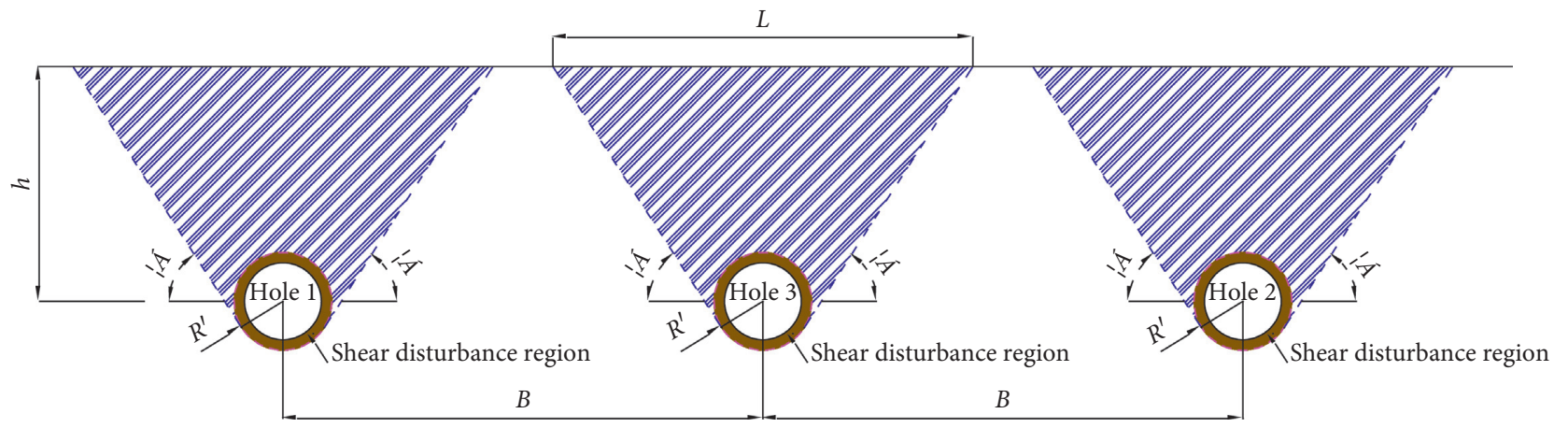

(c)

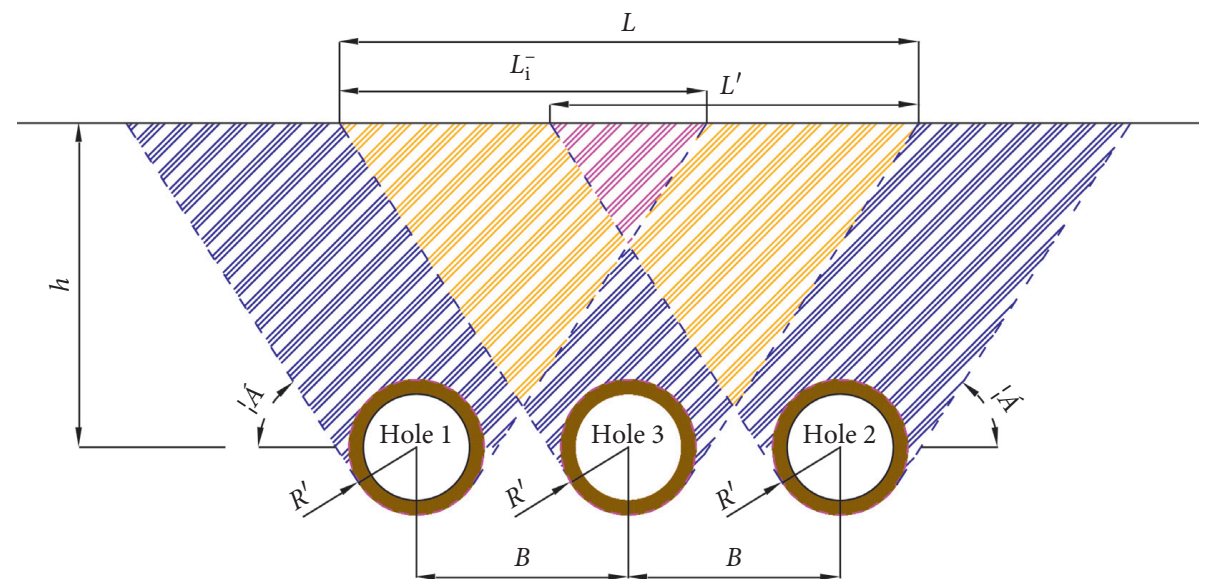

(d)

Figure 4: Schematic diagram of lateral disturbance range of three-hole pipeline jacking. (a) The third hole is located on the outside of the previous two holes and the center spacing is large. (b) The third hole is located on the outside of the previous two holes and the center spacing is small. (c) The third hole is located in the middle of the previous two holes and the center spacing is large. (d) The third hole is located in the middle of the previous two holes and the center spacing is small.

\section{Field Test Scheme}

4.1. Test Content and Layout of Monitoring Points. The field monitoring contents include the earth pressure and pore water pressure of the soil around the pipe jacking group. According to the site construction and environmental conditions, the monitoring section is arranged at $4+368.9$ mileage between No. 4 shaft and No. 5 shaft. To investigate the soil disturbance around the pipe jacking group to the greatest extent, seven monitoring holes are set on the monitoring section. Among them, No. 2, No. 4, and No. 6 monitoring holes are located directly above Hole 1, Hole 2, and Hole 3, respectively. No. 3 and No. 5 monitoring holes are located at the middle of the center spacing, and No. 1 and No. 7 monitoring holes are located at the double center spacing of Hole 1 and Hole 3. Two monitoring points are set at No. 2, No. 4, and No. 6 monitoring holes, and five monitoring points are set at No. 1 , No. 3 , No. 5 , and No. 7 


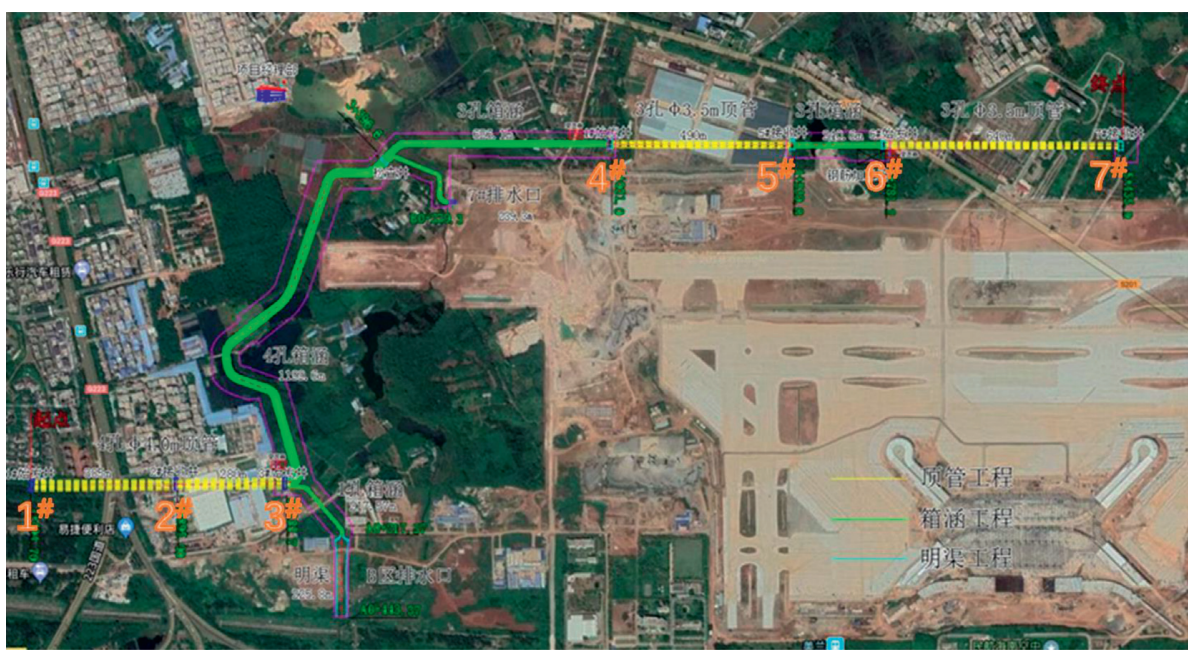

Figure 5: Aerial view of the project.

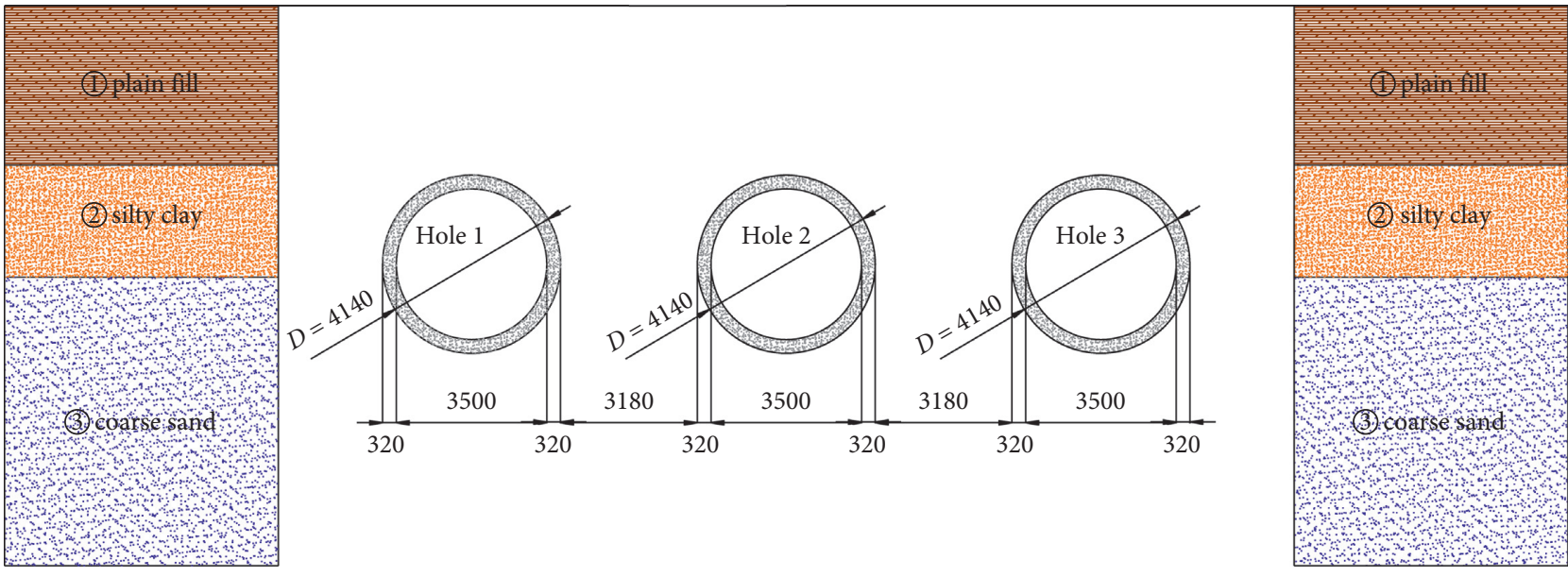

Figure 6: Cross section of pipe jacking group.

TABLE 1: Main geotechnical parameters of soils at the construction site.

\begin{tabular}{lccccc}
\hline Soil layer & Depths $(\mathrm{m})$ & Water content $(\%)$ & Void ratio & Cohesion $(\mathrm{kPa})$ & Internal friction angle $\left(^{\circ}\right)$ \\
\hline (1) plain fill & $0-3.98$ & 30.4 & 0.865 & 27.9 & 16.8 \\
(2) silty clay & $3.98-6.58$ & 25.03 & 0.81 & 14.91 & 15.42 \\
(3) coarse sand & $6.58-13.28$ & & & 8 & \\
\hline
\end{tabular}

monitoring holes. Earth pressure and pore water pressure gauges are arranged above and below at each monitoring point, so there are 7 monitoring holes, 26 monitoring points, and 52 stress gauges in total. The layout of the earth pressure gauge and pore water pressure gauge measuring points is shown in Figure 7. Figure 8 describes the erection and burying of on-site monitoring.

4.2. Test Monitoring Elements and Data Collection. JTM-V2000 vibrating wire earth pressure gauge and JTMV3000 vibrating wire pore water pressure gauge are used as monitoring elements. Its working principle is that the high sensitivity induction membrane produces deflection under the action of load and changes the excited frequency of the metal string of the induction membrane. The load on the earth pressure box and pore water pressure gauge is calculated by using the sensor calibration coefficient. In this project, data acquisition adopts the combination of a 32channel JTM-MV20A data acquisition box and hand-held JTM-10A vibrating wire sensor reader. JTM-MV20A data acquisition box monitors and records the vibration frequency of the metal string every 6 seconds, and ZLY-V1.0 intelligent acquisition cloud platform management system software transmits data online and monitors the scene.

\section{Analysis of Test Results}

5.1. Analysis of Soil Disturbance during the First Hole Excavation. From Nov. 10 to 21, 2019, Hole 1 passed through 


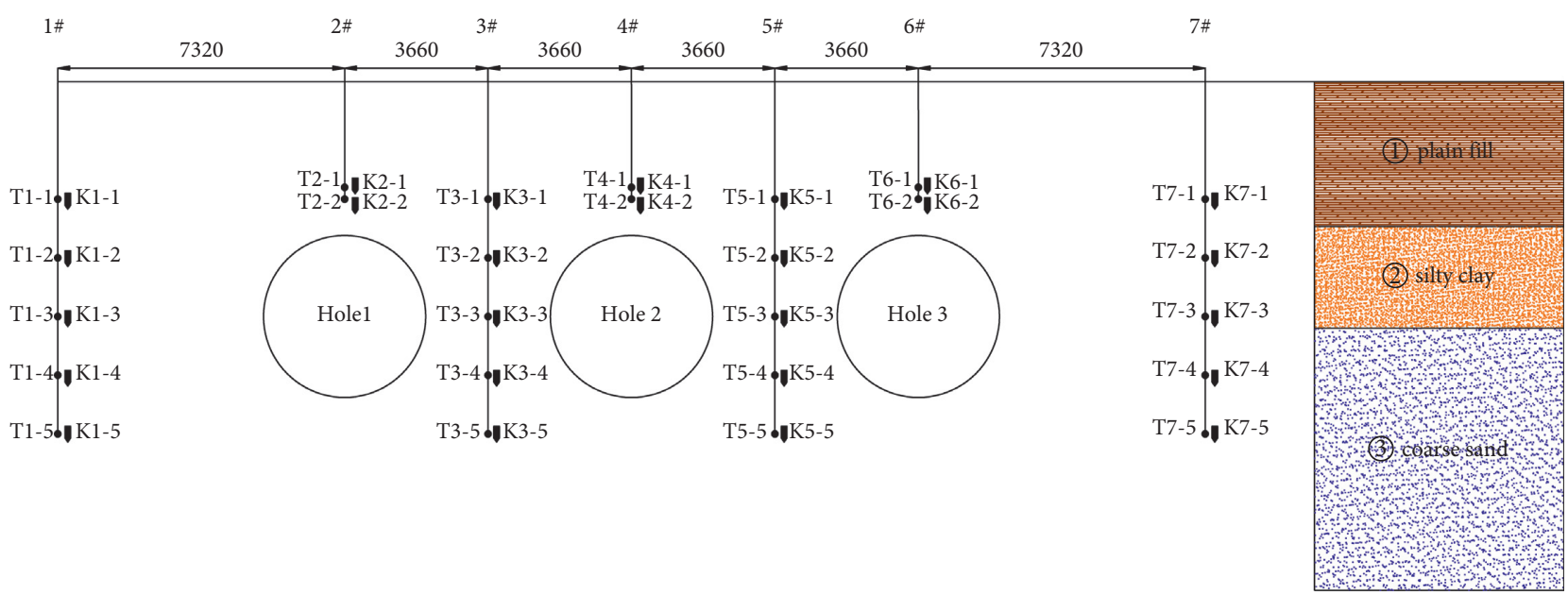

FIgURE 7: Distribution map of monitoring points.

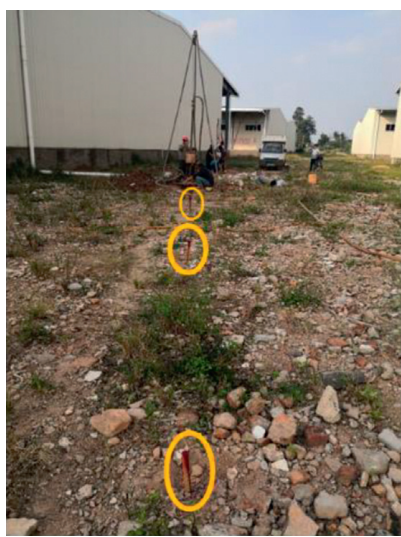

(a)

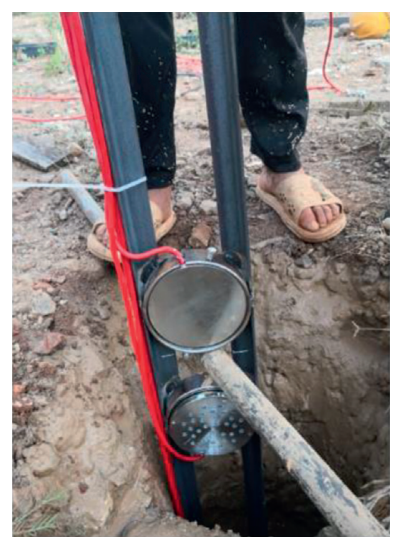

(c)

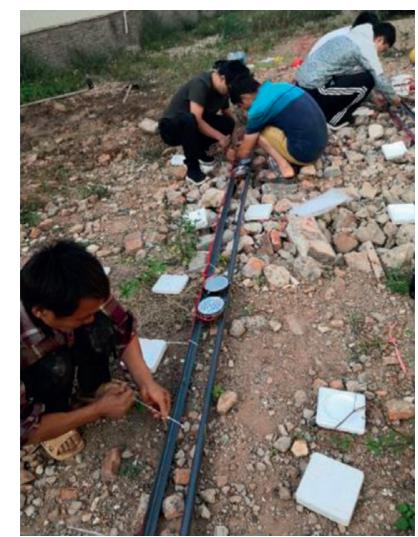

(b)

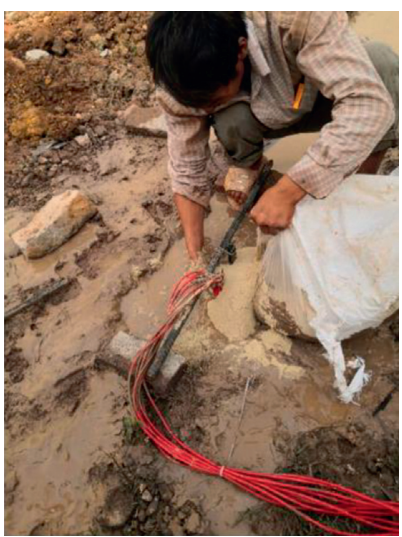

(d)

FIgURE 8: Diagram of monitoring elements erection and burying.

the monitoring section. The earth pressure and pore water pressure of No. 1, 2, 3, and 4 monitoring holes at different depths are recorded in Figures 9 and 10, respectively. And the earth pressure and pore water pressure of Nos. 5, 6, and 7 monitoring holes are unchanged.

It can be seen from Figures 9 and 10 that (1) the pore water pressure and earth pressure of No. 1, 2, 3, and 4 monitoring holes are gradually decreasing. Since Nov. 10, 2019, when field monitoring starts, the tail of MTBM has just left the monitoring section, and the outer diameter of the MTBM is larger than the outer diameter of the first segment, which would form a gap on the outer wall of the segment. At this time, the thixotropic slurry injected from the tail and segment joint has just been injected into the gap, and the hoop supporting has not yet been 


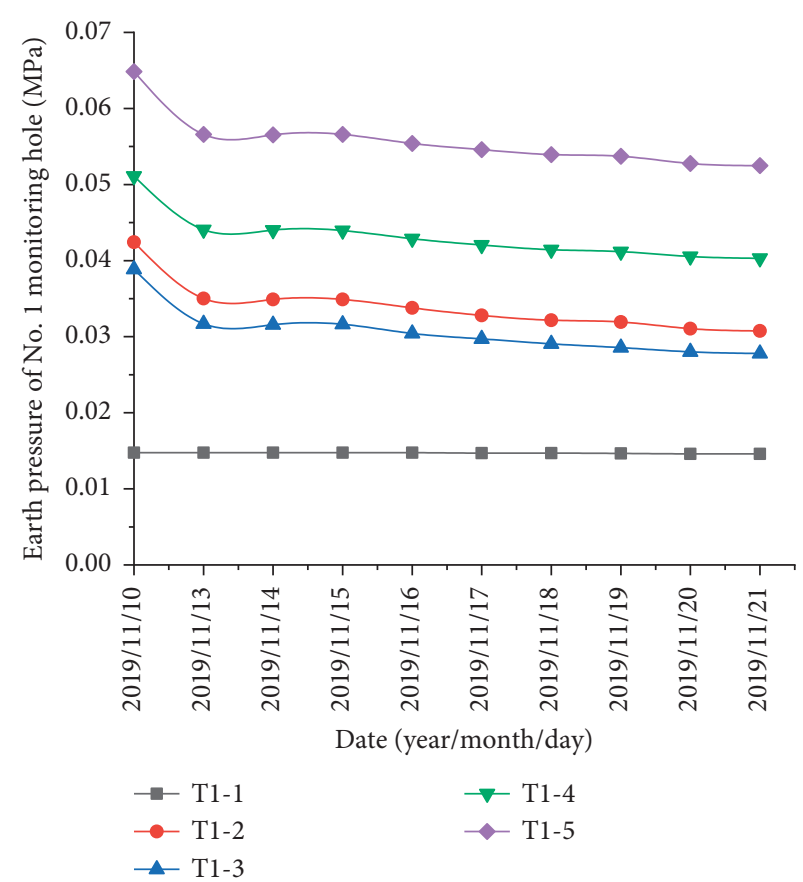

(a)

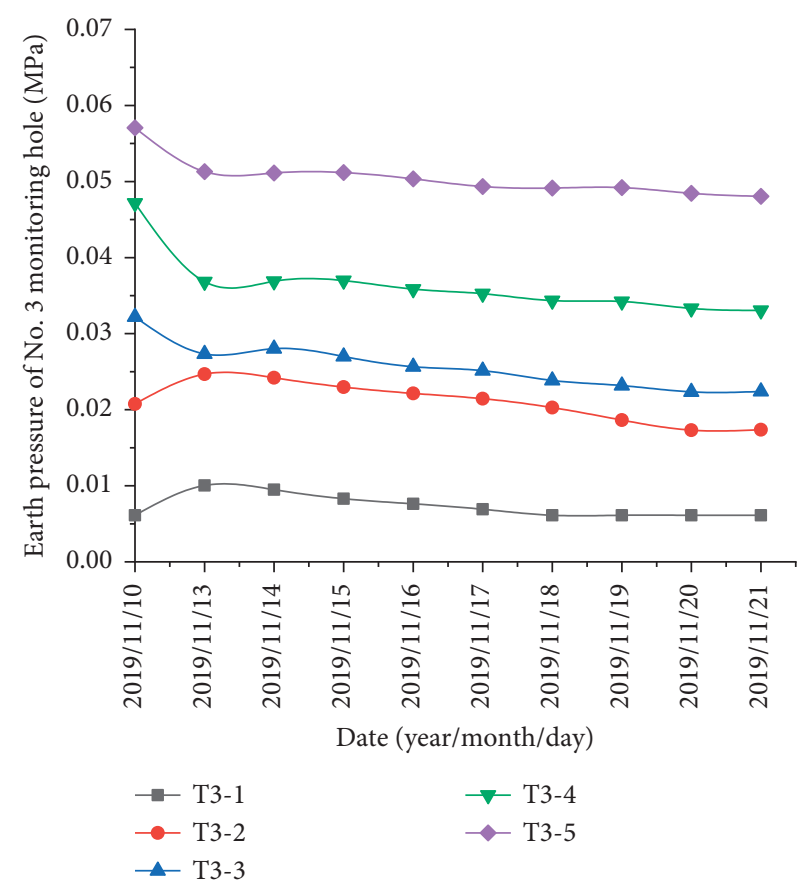

(c)

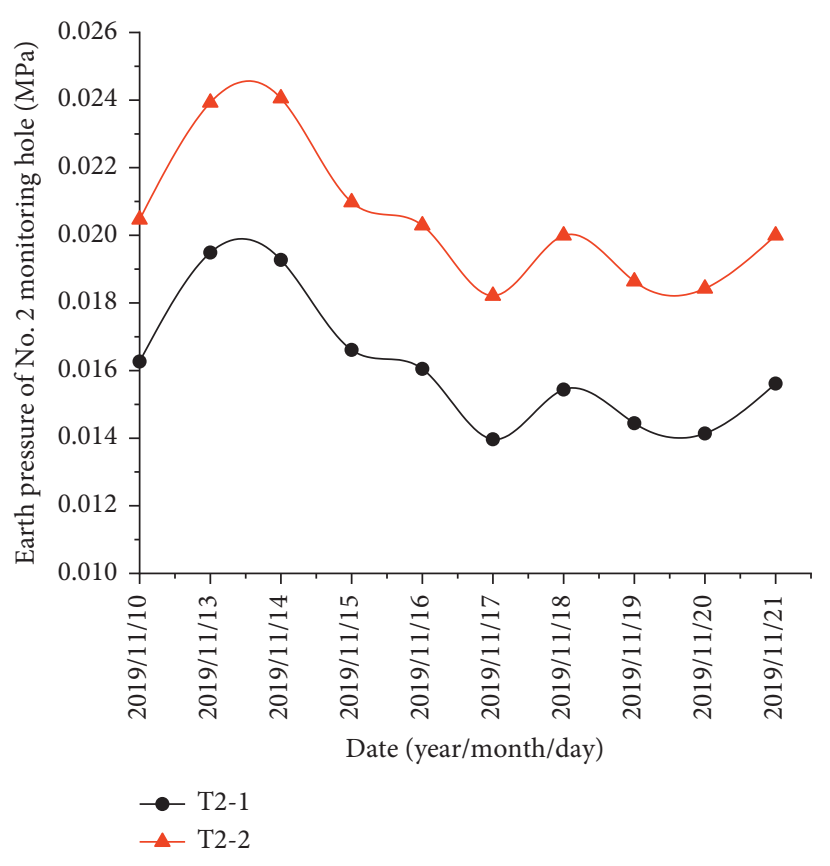

(b)

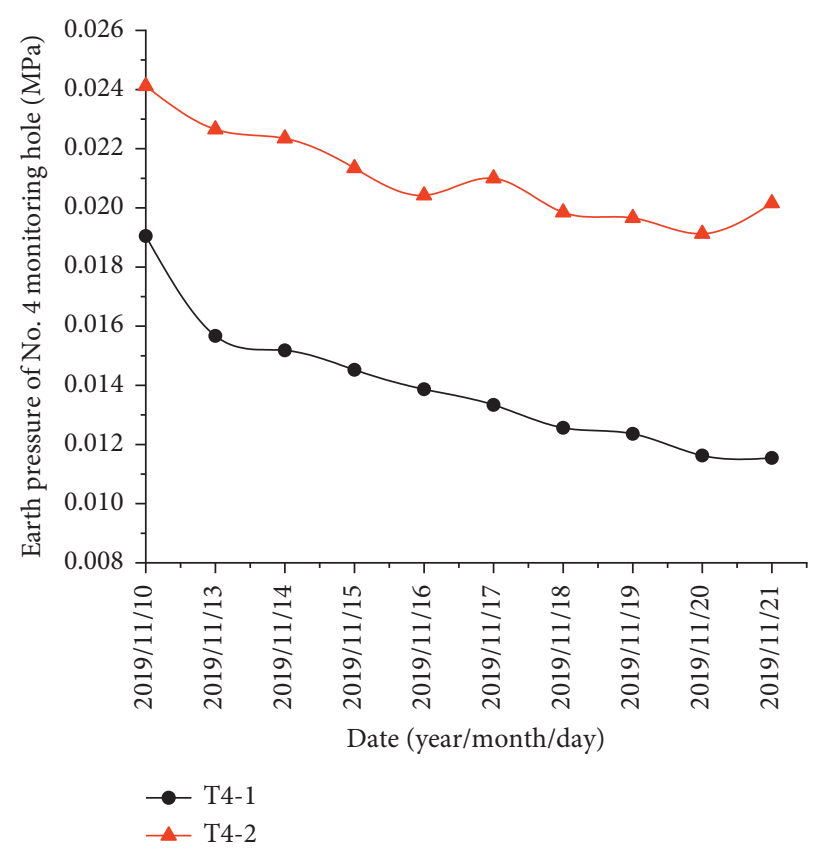

(d)

FIGURE 9: Variation diagram of earth pressure during Hole 1 jacking. (a) Earth pressure of No. 1 monitoring hole. (b) Earth pressure of No. 2 monitoring hole. (c) Earth pressure of No. 3 monitoring hole. (d) Earth pressure of No. 4 monitoring hole.

formed. After the tail of the MTBM comes out, the soil has no capacity to support itself and self-stabilization and fill the void quickly, resulting in the release of soil stress and the dissipation of pore water pressure gradually. (2) The decline level of the earth pressure and pore water pressure of No. 1, No. 2, No. 3, and No. 4 monitoring holes is different. And the pressure reduces to zero between No. 4 and No. 5 monitoring holes.
5.2. Analysis of Soil Disturbance during the Second Hole Excavation. From Dec. 27 to 31, 2019, Hole 3 passed through the monitoring section. The earth pressure and pore water pressure of Nos. 4, 5, 6, and 7 monitoring holes at different depths are recorded in Figures 11(a) and 12, respectively. And the earth pressure and pore water pressure of Nos. 1, 2, and 3 monitoring holes are basically unchanged. 


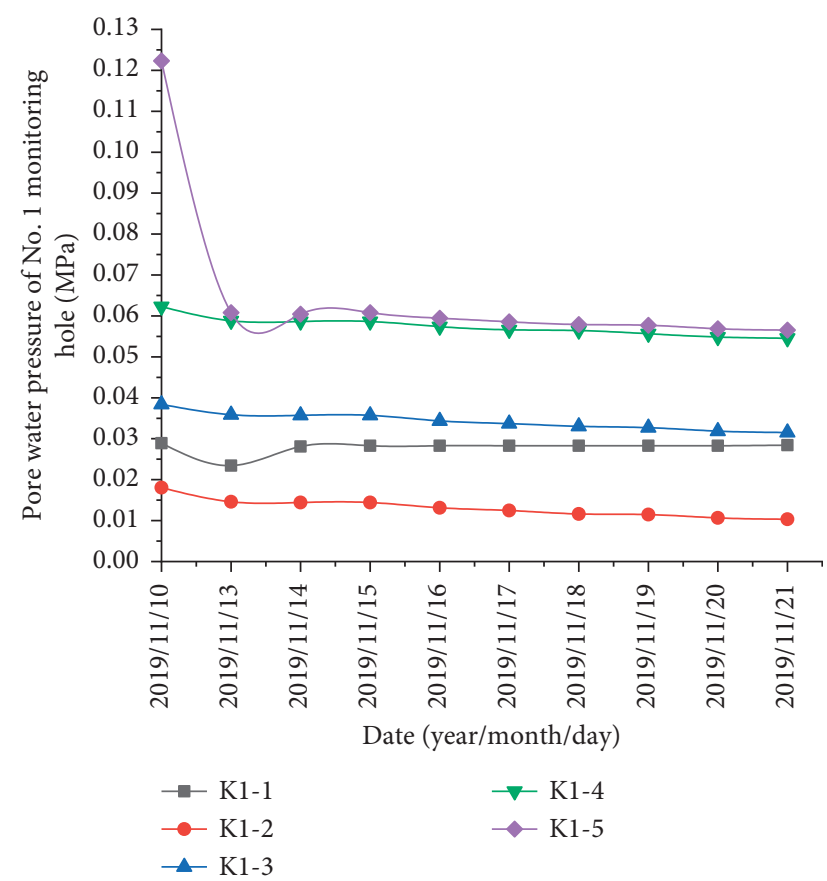

(a)

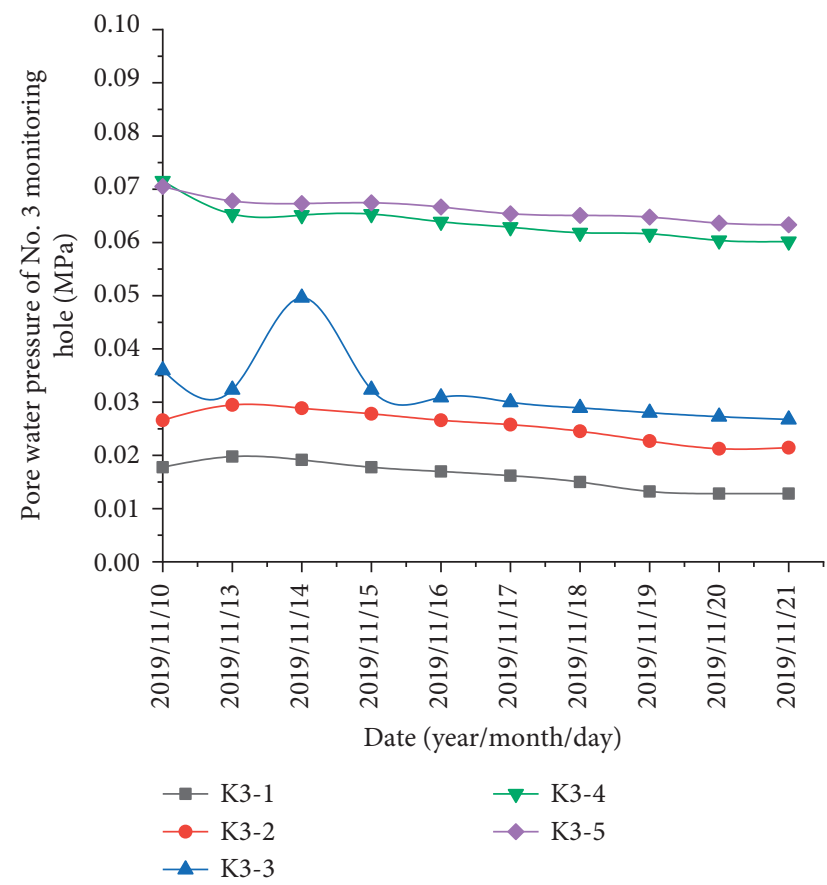

(c)

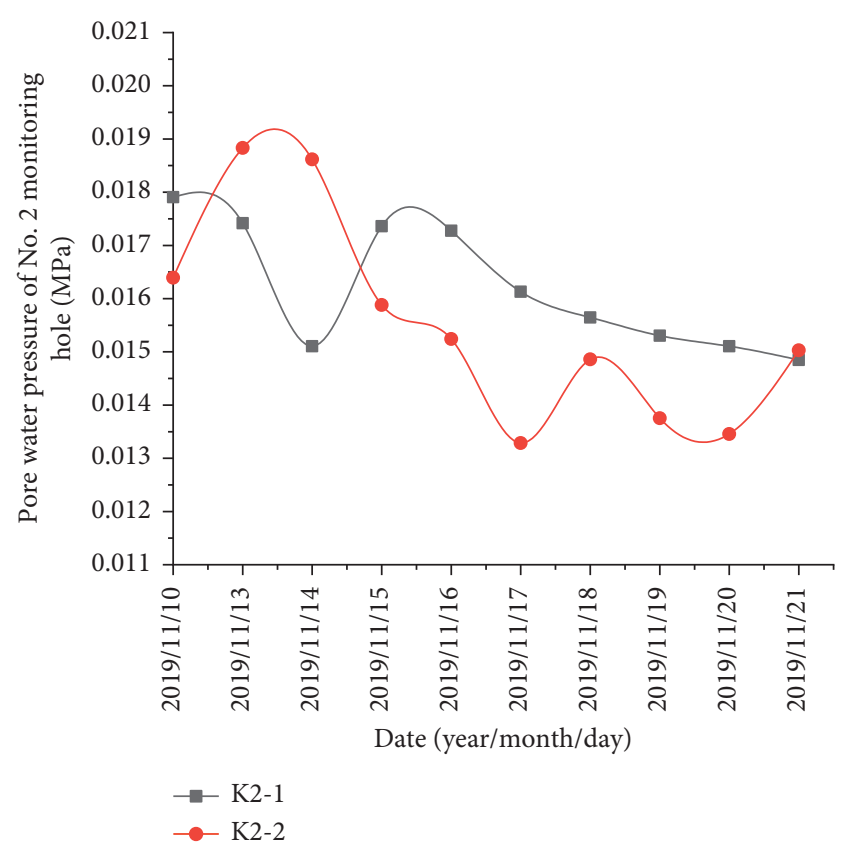

(b)

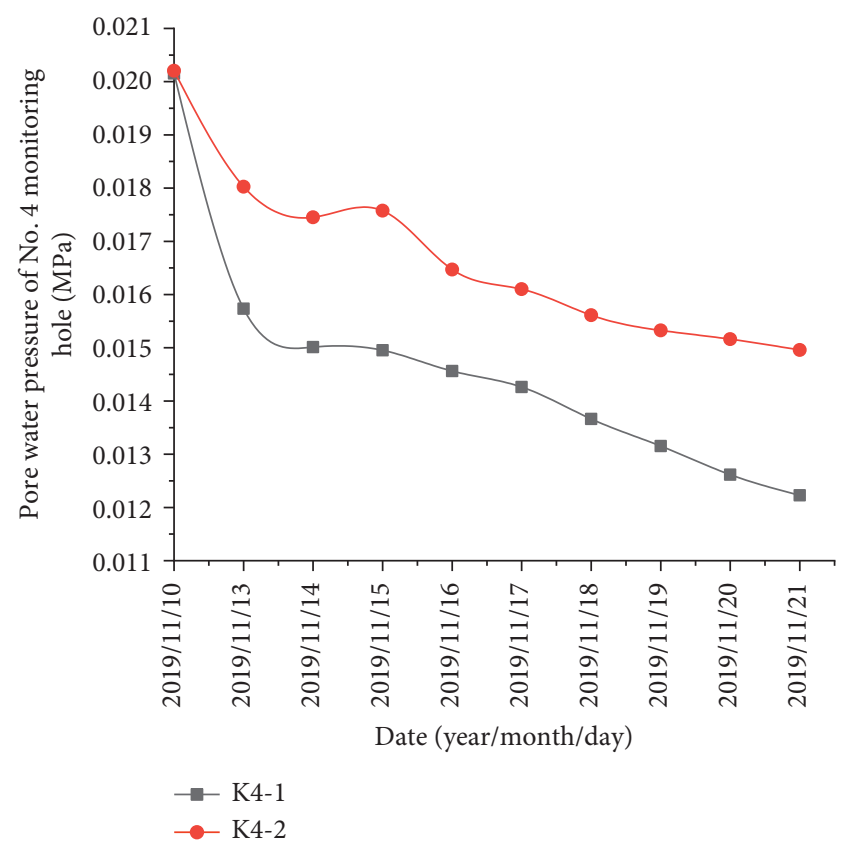

(d)

Figure 10: Variation diagram of pore water pressure during Hole 1 jacking. (a) Pore water pressure of No. 1 monitoring hole. (b) Pore water pressure of No. 2 monitoring hole. (c) Pore water pressure of No. 3 monitoring hole. (d) Pore water pressure of No. 4 monitoring hole.

It can be seen from Figures 11 and 12 that (1) the earth pressure and pore water pressure of Nos. 4, 5, 6, and 7 monitoring holes have changed clearly. Taking No. 6 monitoring hole which is shown in Figure 8(c) as an example, the pressure basically remains unchanged for a long time before it arrives at the monitoring section ahead of $15 \mathrm{~m}$. When it arrives at the monitoring section ahead of $15 \mathrm{~m}$, the pressure begins to increase sharply. When it reaches the monitoring section, the pressure is still fluctuating, but slightly gentle than before. After leaving the monitoring section for $10 \mathrm{~m}$, the pressure decreases slowly. (2) The range and intensity of variation of earth pressure and pore water pressure in No. 4, No. 5, No. 6, and No. 7 monitoring holes are different. Between No. 3 and No. 4 monitoring holes, the pressure value decays clearly. 


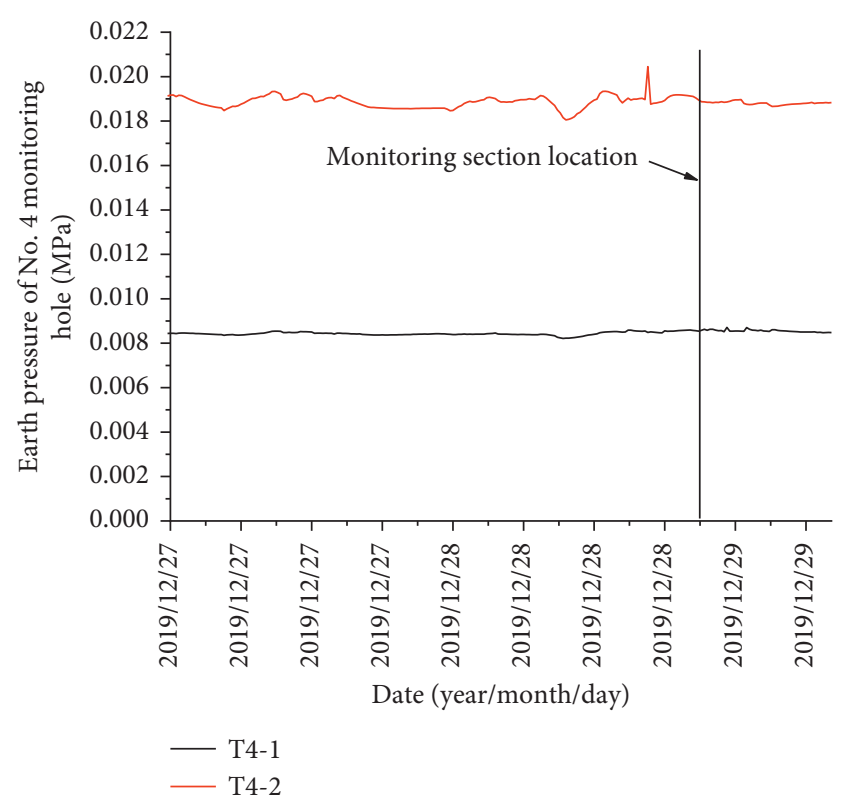

(a)

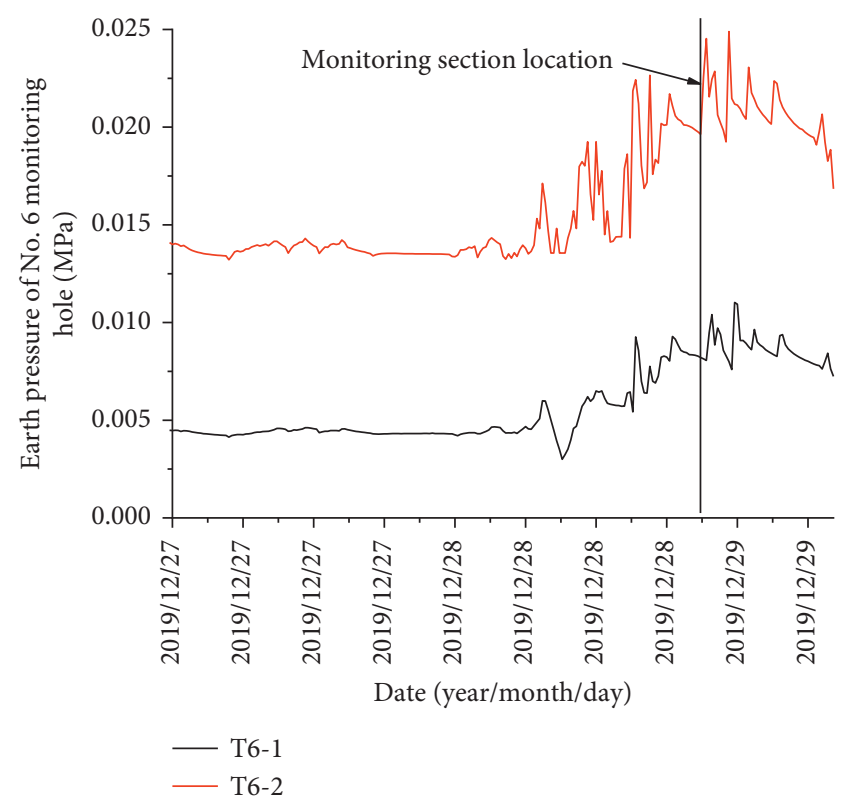

(c)

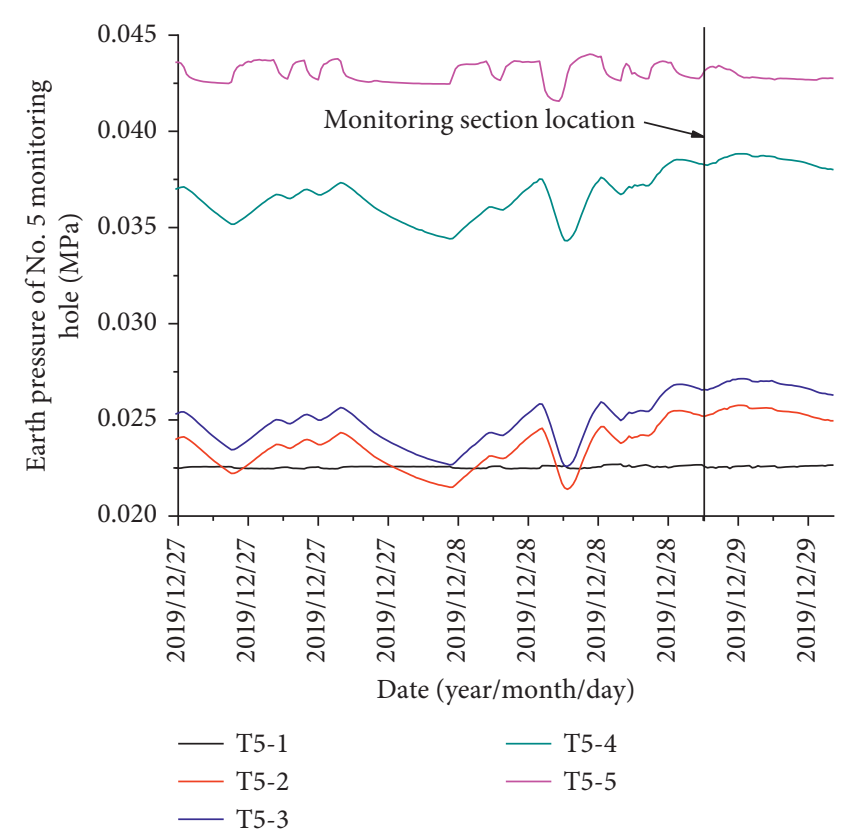

(b)

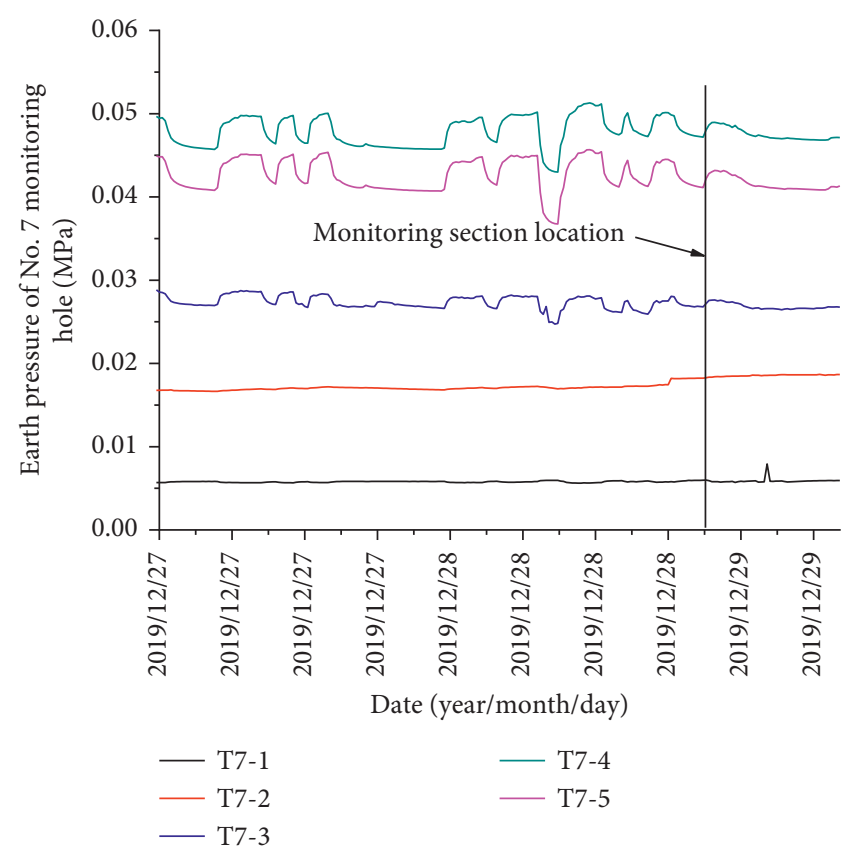

(d)

Figure 11: Variation diagram of earth pressure during Hole 3 jacking. (a) Earth pressure of No. 4 monitoring hole. (b) Earth pressure of No. 5 monitoring hole. (c) Earth pressure of No. 6 monitoring hole. (d) Earth pressure of No. 7 monitoring hole.

5.3. Analysis of Soil Disturbance during the Third Hole Excavation. From Apr. 10 to 15, 2020, Hole 2 passed through the monitoring section. The earth pressure and pore water pressure of Nos. 2, 3, 4, 5, and 6 monitoring holes at different depths are recorded in Figures 13 and 14, respectively. And the earth pressure and pore water pressure of Nos. 1 and 7 monitoring holes are basically unchanged.

It can be seen from Figures 13 and 14 that (1) the earth pressure and pore water pressure of Nos. 2, 3, 4, 5, and 6 monitoring holes have some changes before and after reaching the monitoring section. And its disturbance law near the monitoring section with the change of horizontal jacking distance is basically the same as that of Hole 3. (2) The amplitude and intensity of variation of soil pressure and pore water pressure in No. 2, 3, 4, 5, and 6 monitoring holes are different. Between No. 1 and No. 2 monitoring holes and between No. 6 and No. 7 monitoring holes, the pressure decays clearly. 


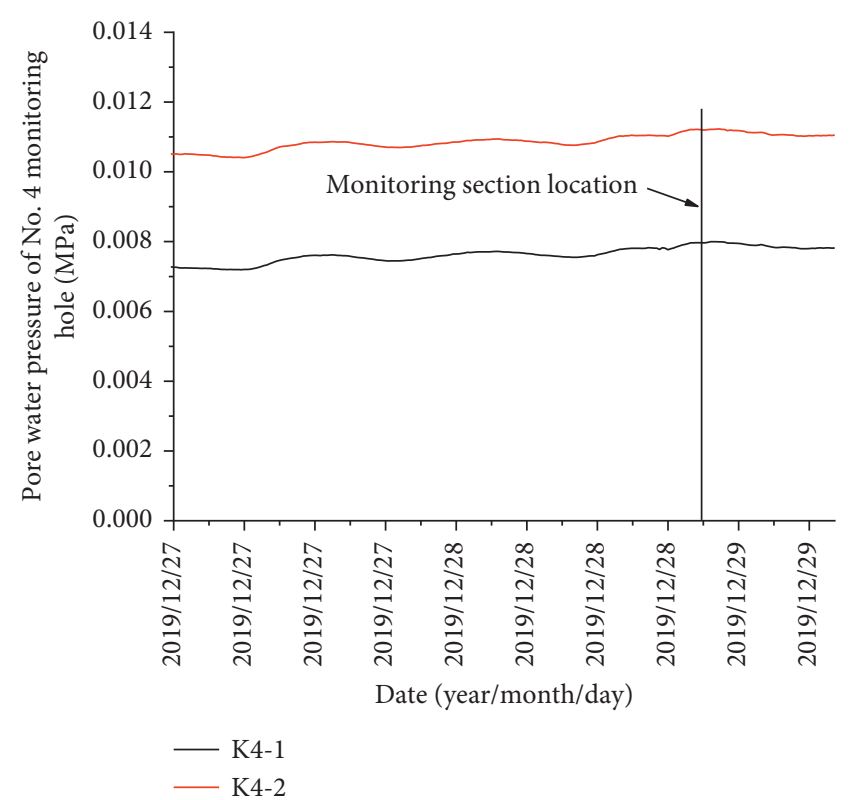

(a)

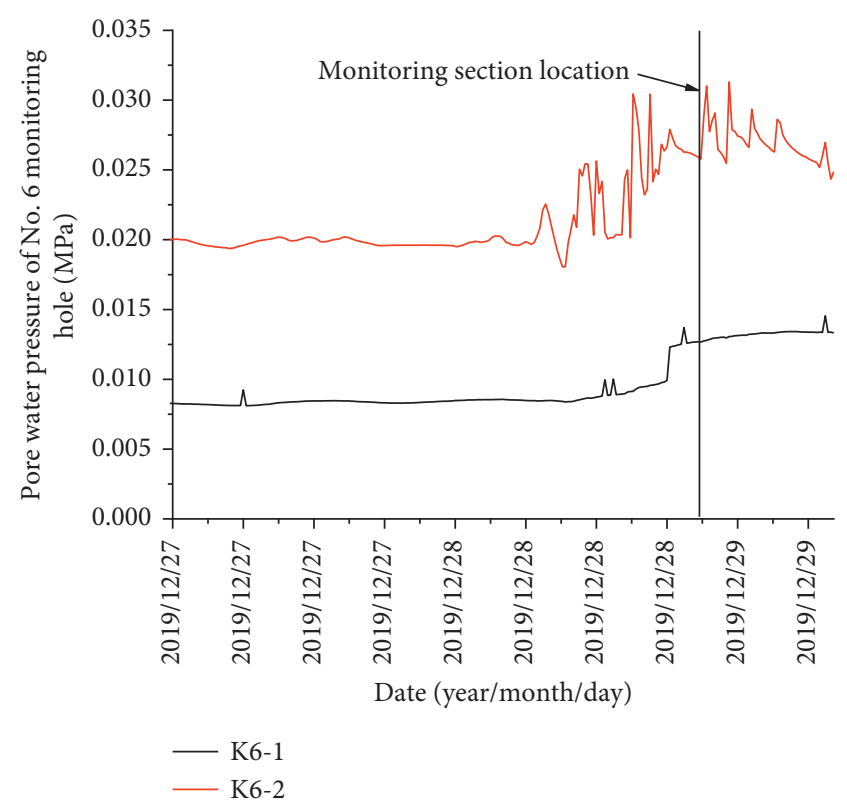

(c)

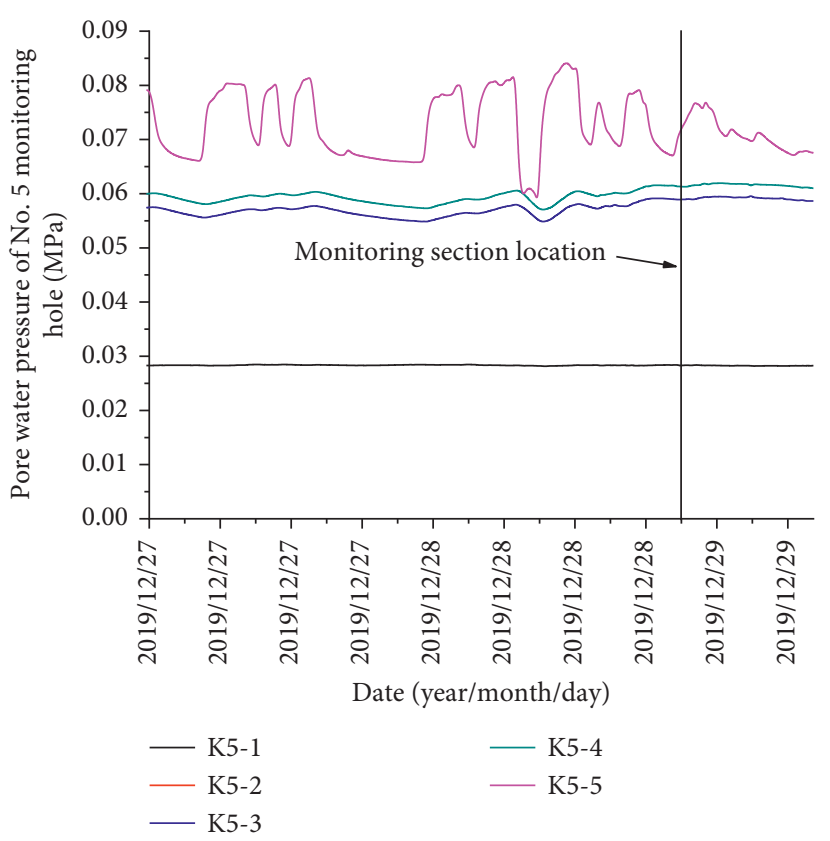

(b)

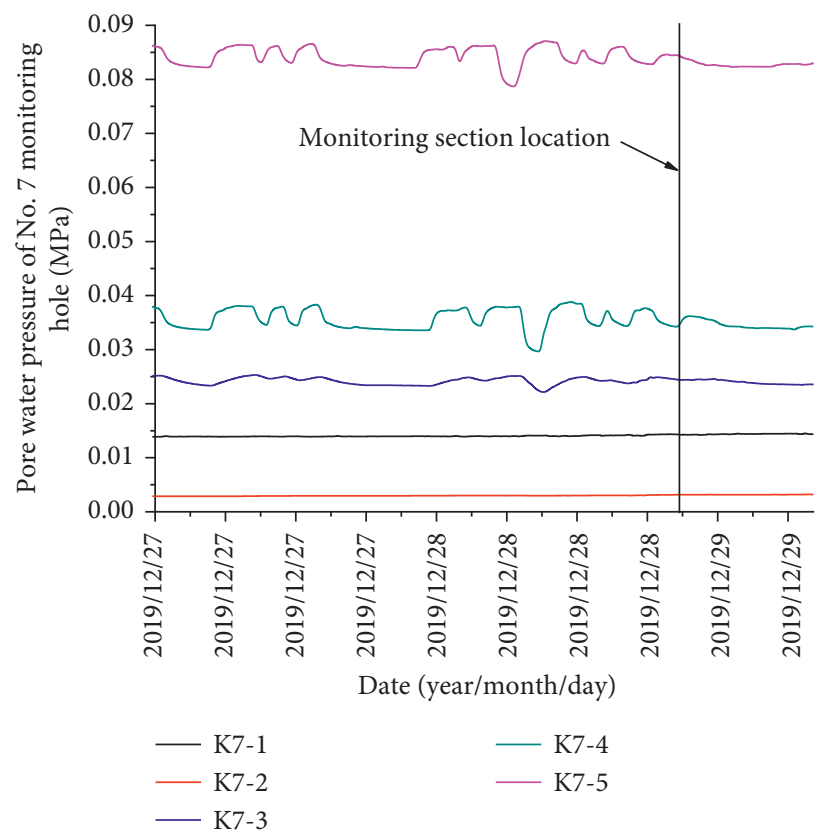

(d)

FIGURE 12: Variation diagram of pore water pressure during Hole 3 jacking. (a) Pore water pressure of No. 4 monitoring hole. (b) Pore water pressure of No. 5 monitoring hole. (c) Pore water pressure of No. 6 monitoring hole. (d) Pore water pressure of No. 7 monitoring hole.

From the field test data, it can be seen that when the head of MTBM excavates through the monitoring section in sequence, the stress field of soil around the monitoring section fluctuates in varying degrees with the change of the horizontal jacking distance, and the change laws of soil pressure and pore water pressure are completely consistent. The horizontal jacking distance affect not only the soil disturbance but also the spacing of pipeline group and buried depth. Therefore, it is necessary to deeply analyze the lateral soil disturbance range and the soil disturbance degree of single-hole, double-hole, and three-hole jacking.

5.4. Analysis of the Lateral Disturbance Range and Disturbance Superposition. In this project, the pipeline group excavates in sequence, and the third hole excavates in the middle of the previous two holes, whose construction sequence is the same as that in Figure 4(d). Ignoring the 


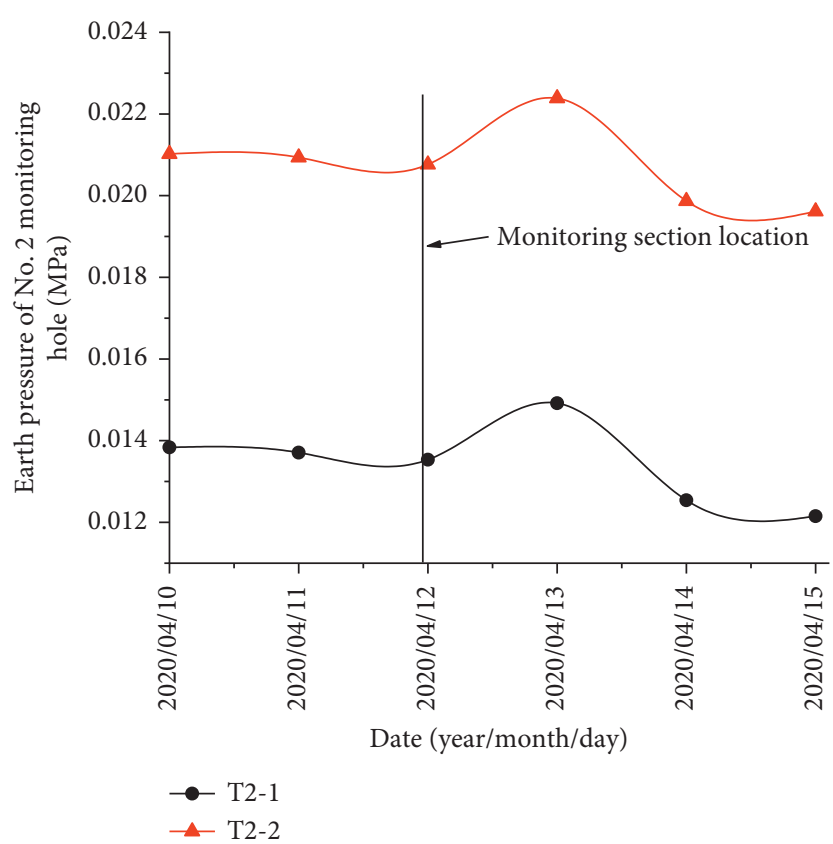

(a)

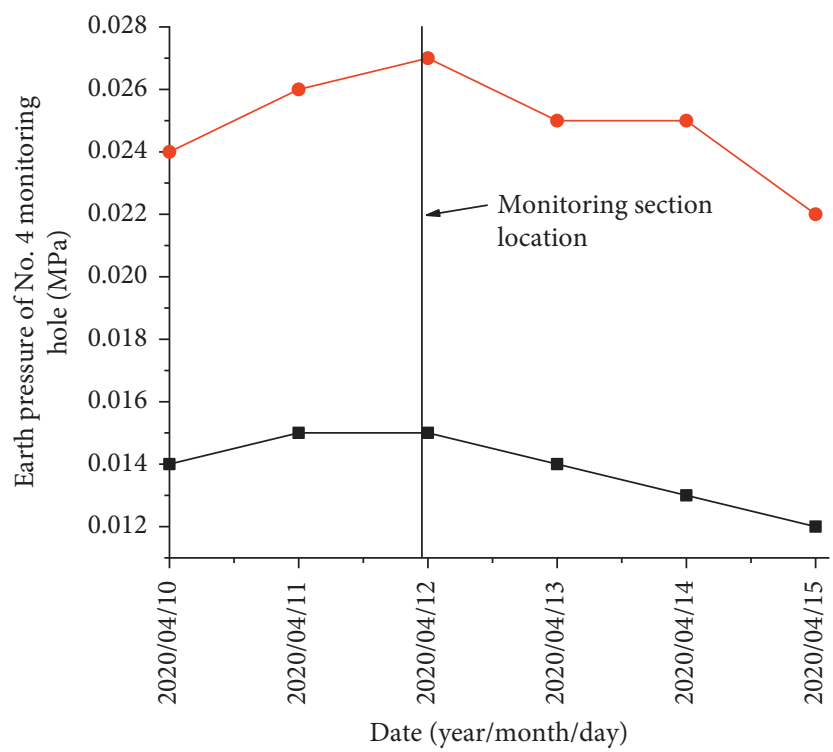

- $\mathrm{T} 4-1$

- T4-2

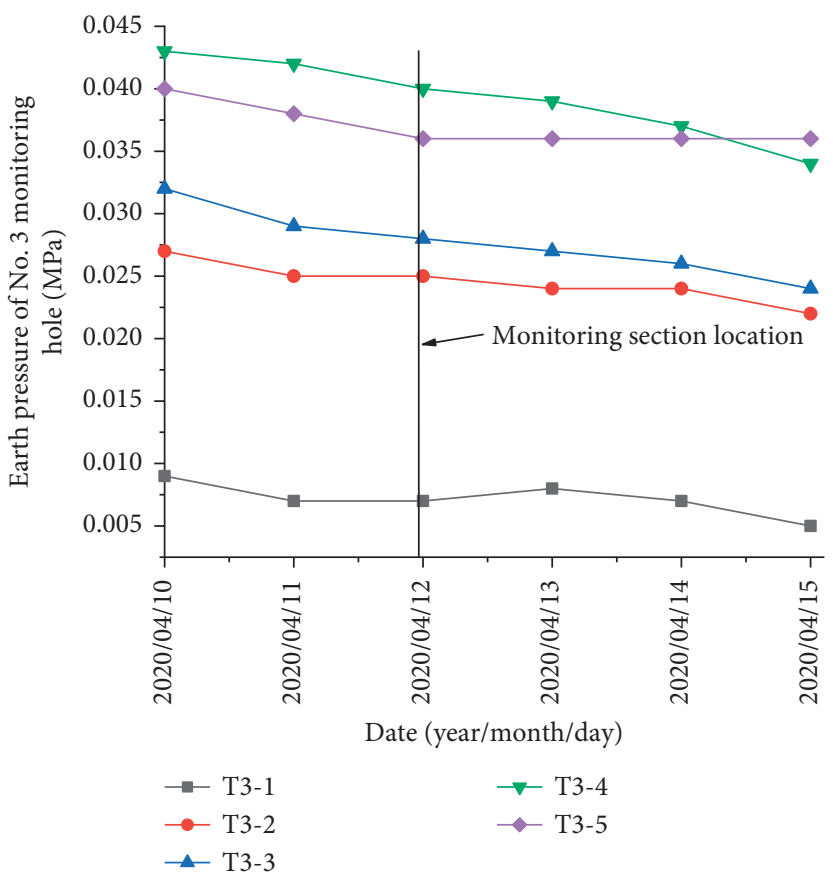

(b)

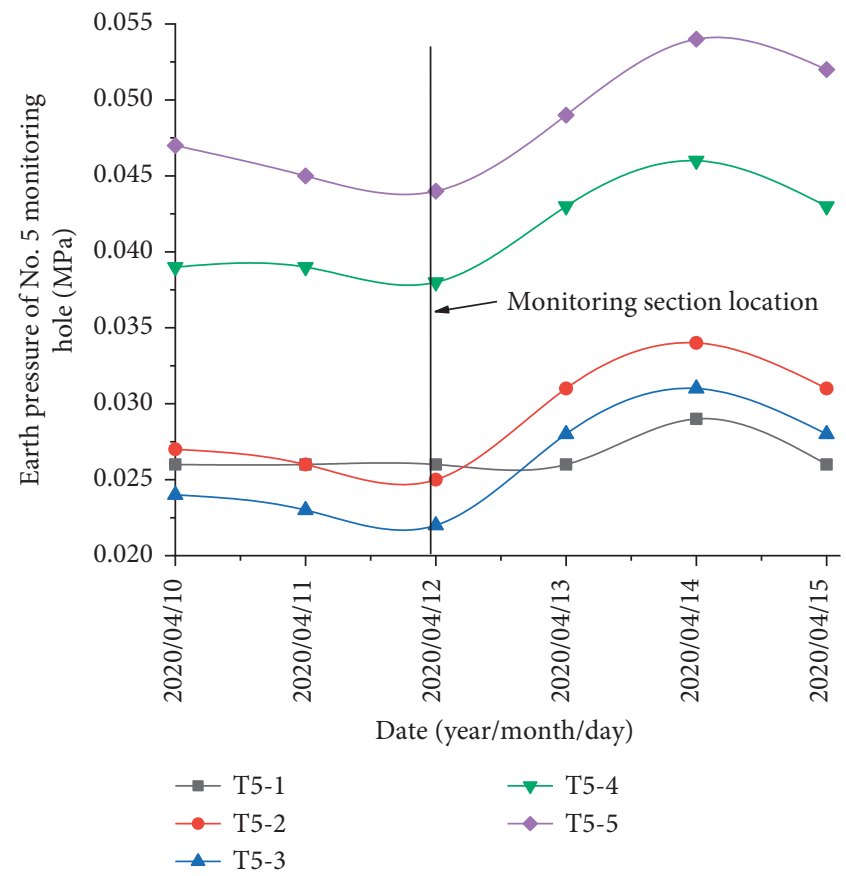

(d)

Figure 13: Continued. 


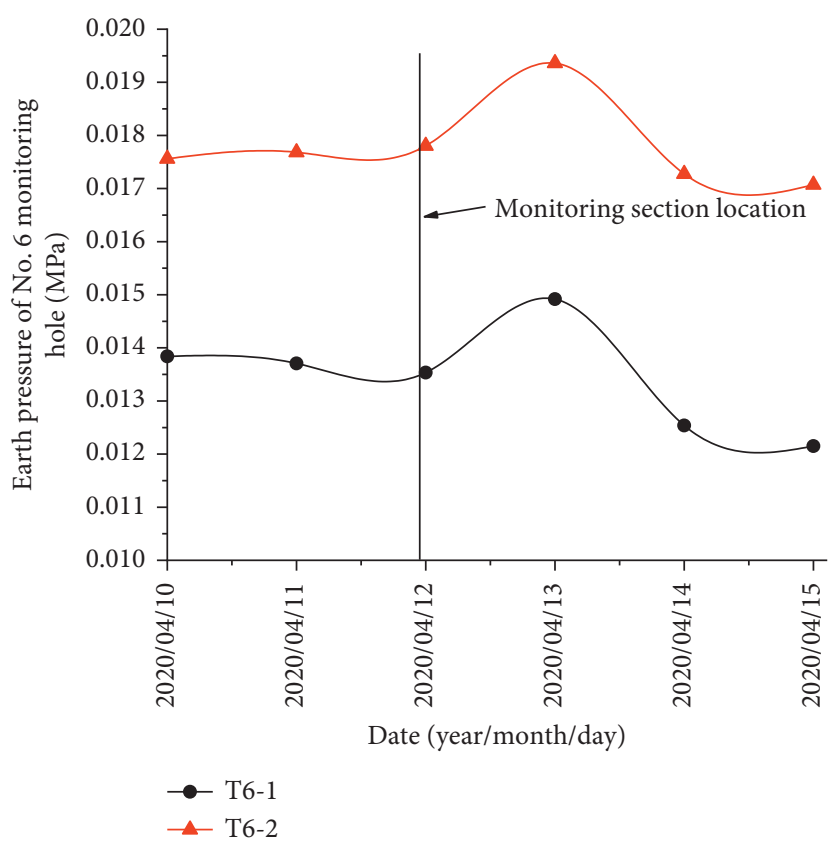

(e)

FIGURE 13: Variation diagram of earth pressure during Hole 2 jacking. (a) Earth pressure of No. 2 monitoring hole. (b) Earth pressure of No. 3 monitoring hole. (c) Earth pressure of No. 4 monitoring hole. (d) Earth pressure of No. 5 monitoring hole. (e) Earth pressure of No. 6 monitoring hole.

influence of soil structure, jacking speed, and other factors, the lateral disturbance range and disturbance overlapping area of single-hole, double-hole, and three-hole jacking can be determined, respectively. The calculation results are shown in Table 2 and Figure 15.

It can be seen from the table and figure that when Hole 1 excavates, its lateral disturbance range is $15.4 \mathrm{~m}$ and its disturbance can affect the earth pressure and pore water pressure at No. 1, 2, 3, and 4 monitoring holes, when Hole 3 excavates, its lateral disturbance range is $15.4 \mathrm{~m}$ and its disturbance can affect the earth pressure and pore water pressure at Nos. 4, 5, 6, and 7 monitoring holes, and when Hole 2 excavates, disturbance overlapping appears due to the small center spacing, its overlapping area range is $8.08 \mathrm{~m}$, and its disturbance can affect the earth pressure and pore water pressure at Nos. 2, 3, 4, 5, and 6 monitoring holes. And the theoretical calculation results are consistent with the above field test data.

\section{Evaluation of Soil Disturbance Degree}

Based on the field test data, with the help of disturbance evaluation method, the disturbance degree of soil can be analyzed [34, 35], and the influence of lateral spacing perpendicular to the jacking direction, the buried depth, and disturbance overlap effect on soil disturbance can be deeply investigated. In this paper, the evaluation of soil disturbance degree based on pore water pressure is adopted. The stress disturbance degree of soil can be expressed as

$$
\lambda_{d}=1-\frac{u}{u_{0}}
$$

where $\lambda_{d}$ is the degree of soil disturbance and $u_{0}$ and $u$ are the pore water pressure before and after disturbance.

6.1. Evaluation of the Influence of the Lateral Spacing Perpendicular to the Jacking Direction on the Disturbance Degree. When the three holes excavate in turn, the monitoring points under the same buried depth are taken to analyze the soil disturbance degree of different lateral spacing, and the results are shown in Figure 16. When Hole 1 excavates, the soil disturbance of No. 2 monitoring hole is the most obvious, followed by No. 3 monitoring hole, and No. 4 and No. 1 monitoring holes are the least. When Hole 3 excavates, the soil disturbance of No. 6 monitoring hole is the most obvious, followed by No. 5 monitoring hole, and No. 4 and No. 7 monitoring holes are the minimum. When Hole 2 excavates, the soil disturbance of No. 4 monitoring hole is the most obvious, followed by No. 3 and No. 5 monitoring holes, and No. 2 and No. 6 monitoring holes are the least. This shows that the closer to the pipe, the more obvious the soil disturbance during the single-hole, double-hole, and threehole jacking. Moreover, the soil disturbance on the top of pipe jacking is more obvious than that on the side due to the loose structure of the overlying soil. 


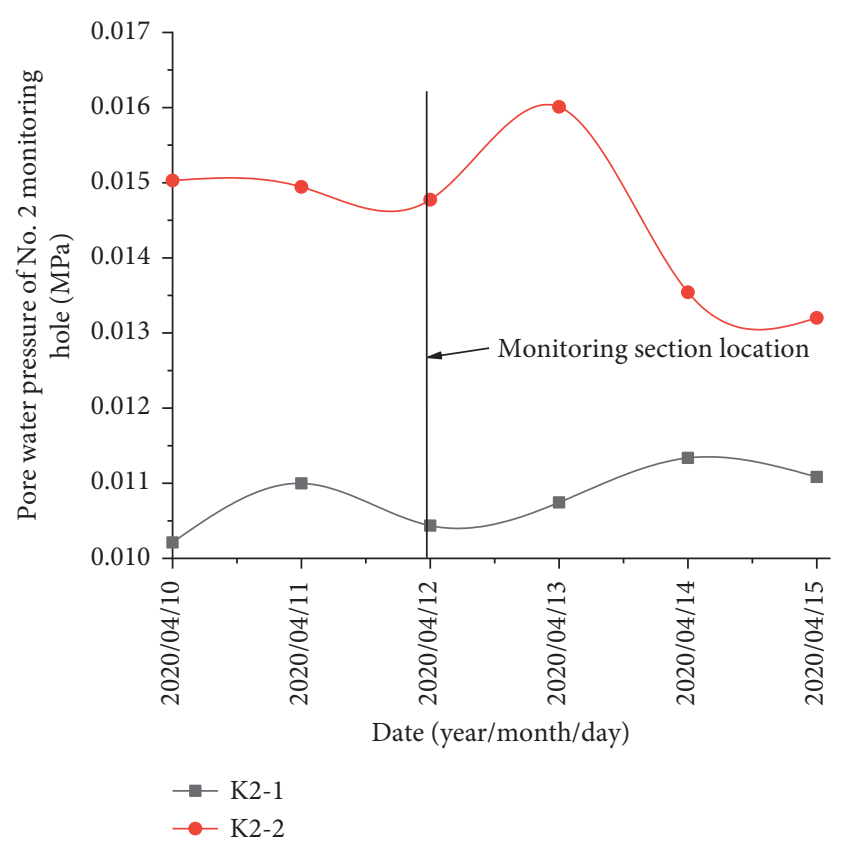

(a)

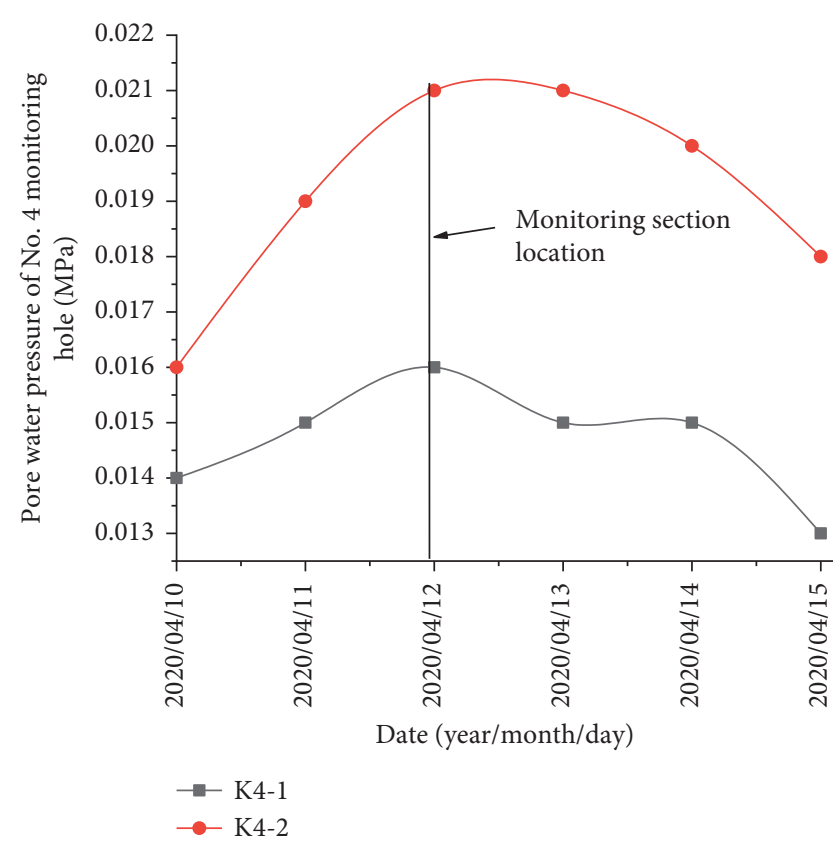

(c)

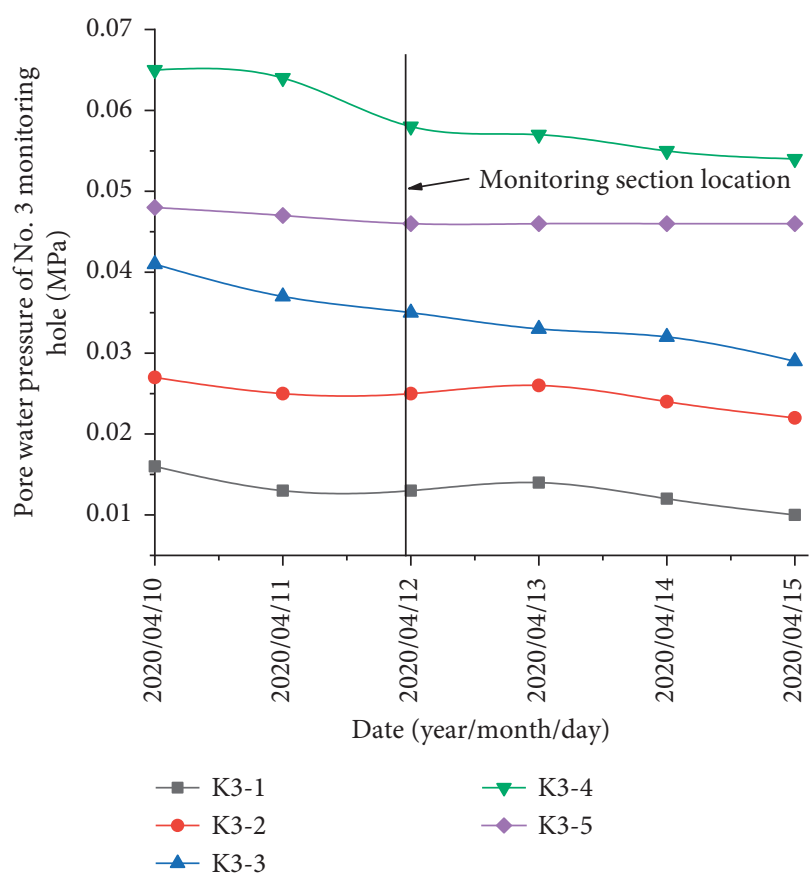

(b)

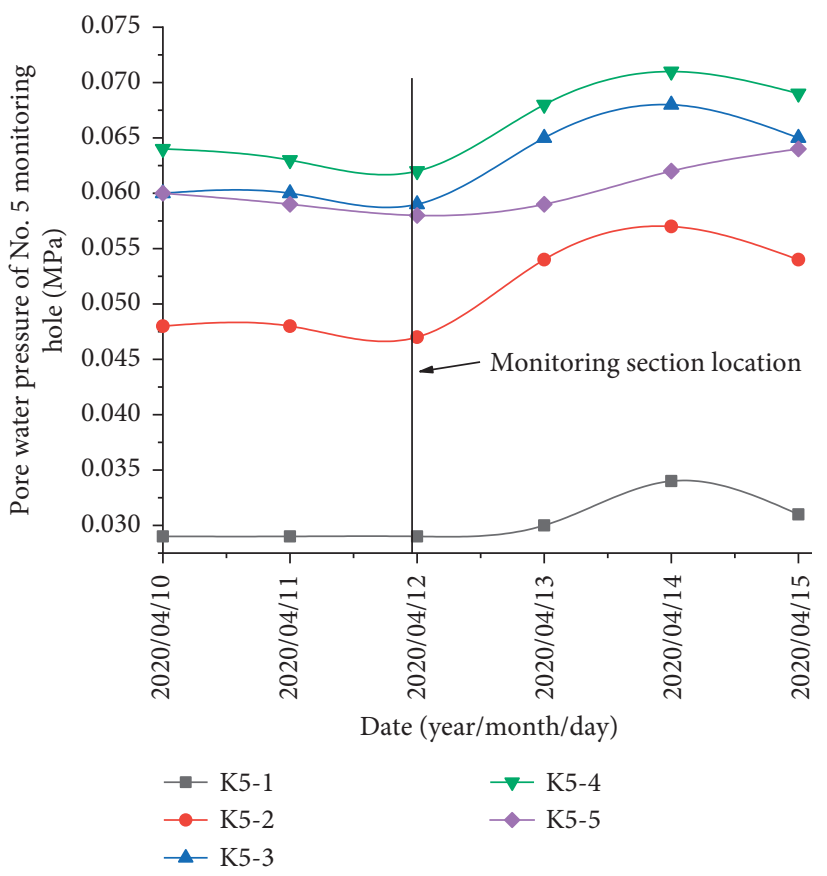

(d)

Figure 14: Continued. 


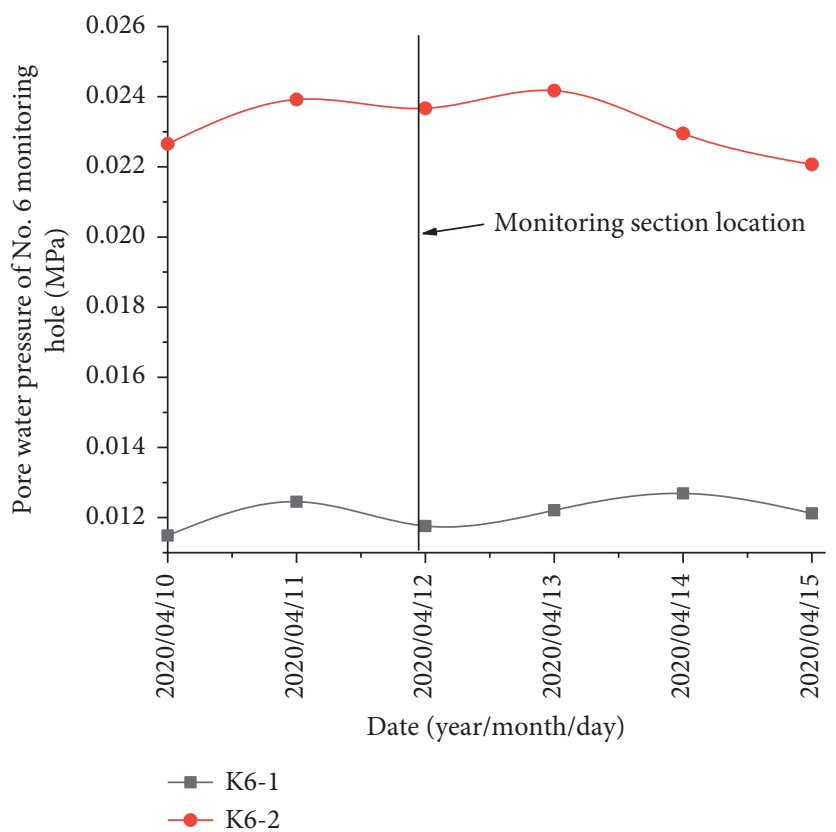

(e)

Figure 14: Variation diagram of pore water pressure during Hole 2 jacking. (a) Pore water pressure of No. 2 monitoring hole. (b) Pore water pressure of No. 3 monitoring hole. (c) Pore water pressure of No. 4 monitoring hole. (d) Pore water pressure of No. 5 monitoring hole. (e) Pore water pressure of No. 6 monitoring hole.

TABLE 2: Calculation table of lateral disturbance range and overlapping range.

\begin{tabular}{|c|c|c|c|c|c|c|}
\hline $\begin{array}{l}\text { Jacking } \\
\text { sequence }\end{array}$ & $\begin{array}{l}\text { Weighted value } \\
\text { of internal } \\
\text { friction angle }\end{array}$ & $\begin{array}{l}\text { The horizontal } \\
\text { elevation angle of the } \\
\text { boundary line }\left(^{\circ}\right)\end{array}$ & $\begin{array}{l}\text { The radius of } \\
\text { disturbance zone } \\
(\mathrm{m})\end{array}$ & Disturbance criteria & $\begin{array}{c}\text { Lateral } \\
\text { disturbance } \\
\text { rang }(\mathrm{m})\end{array}$ & $\begin{array}{c}\text { Overlapping } \\
\text { area range }(\mathrm{m})\end{array}$ \\
\hline $\begin{array}{l}\text { Hole } 1 \\
\text { Hole } 3 \\
\text { Hole } 2\end{array}$ & 16.8 & 52 & 2.47 & $\begin{array}{l}B>2 h \operatorname{ctg} \alpha+\left(2 R^{\prime} / \sin \alpha\right) \\
B<2 h c t g \alpha+\left(2 R^{\prime} / \sin \alpha\right)\end{array}$ & $\begin{array}{l}L_{1}=15.4 \\
L_{2}=15.4\end{array}$ & $\begin{array}{c}L_{1}^{\prime}=0 \\
L_{2}^{\prime}=0.76 \\
L_{3}^{\prime}=8.08\end{array}$ \\
\hline
\end{tabular}

6.2. Evaluation of the Influence of the Buried Depth on the Disturbance Degree. Take the soil disturbance degree analysis of No. 4 monitoring hole under different buried depths, and the results are shown in Figure 17. After comparison, it is found that the larger the buried depth is, the closer it is to the top surface of the pipelines, the higher the degree of soil disturbance is, and the more severe the soil disturbance is.

6.3. Evaluation of the Influence of Overlap on the Disturbance Degree. Comparing the soil disturbance degree of 


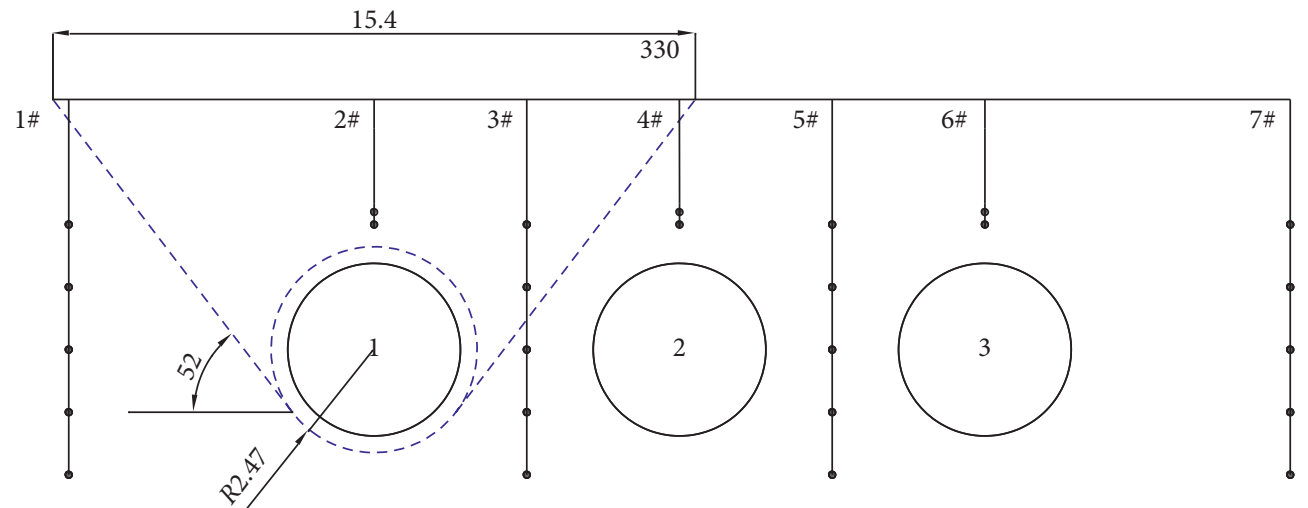

(a)

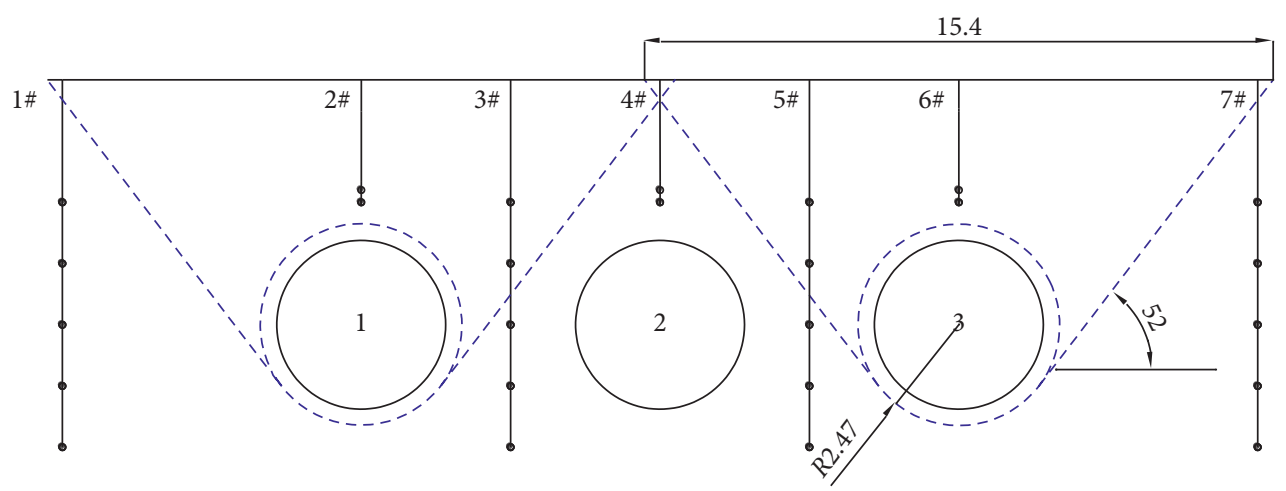

(b)

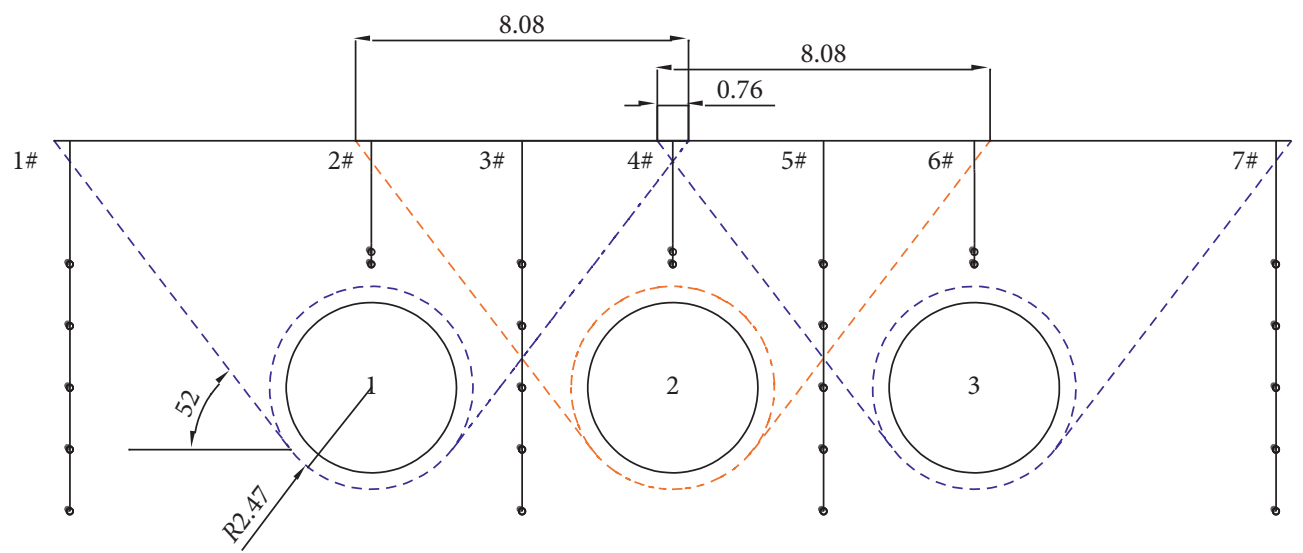

(c)

Figure 15: Calculation map of lateral disturbance range and overlapping range. (a) Hole 1 excavates. (b) Hole 3 excavates. (c) Hole 2 excavates.

monitoring point 3-1 when Hole 1 and Hole 2 excavate through, respectively, the disturbance overlap effect of double-hole jacking can be obtained, and the result is shown in Figure 18.

It can be seen that, in the double-hole disturbance overlap area, the soil disturbance caused by the second hole is larger than that caused by the first hole, but the disturbance intensity is smaller. This is because the soil structure is more loose when the second hole excavates, and the disturbance caused by the loading and unloading of the soil during jacking is less obvious than that of the original soil before. 

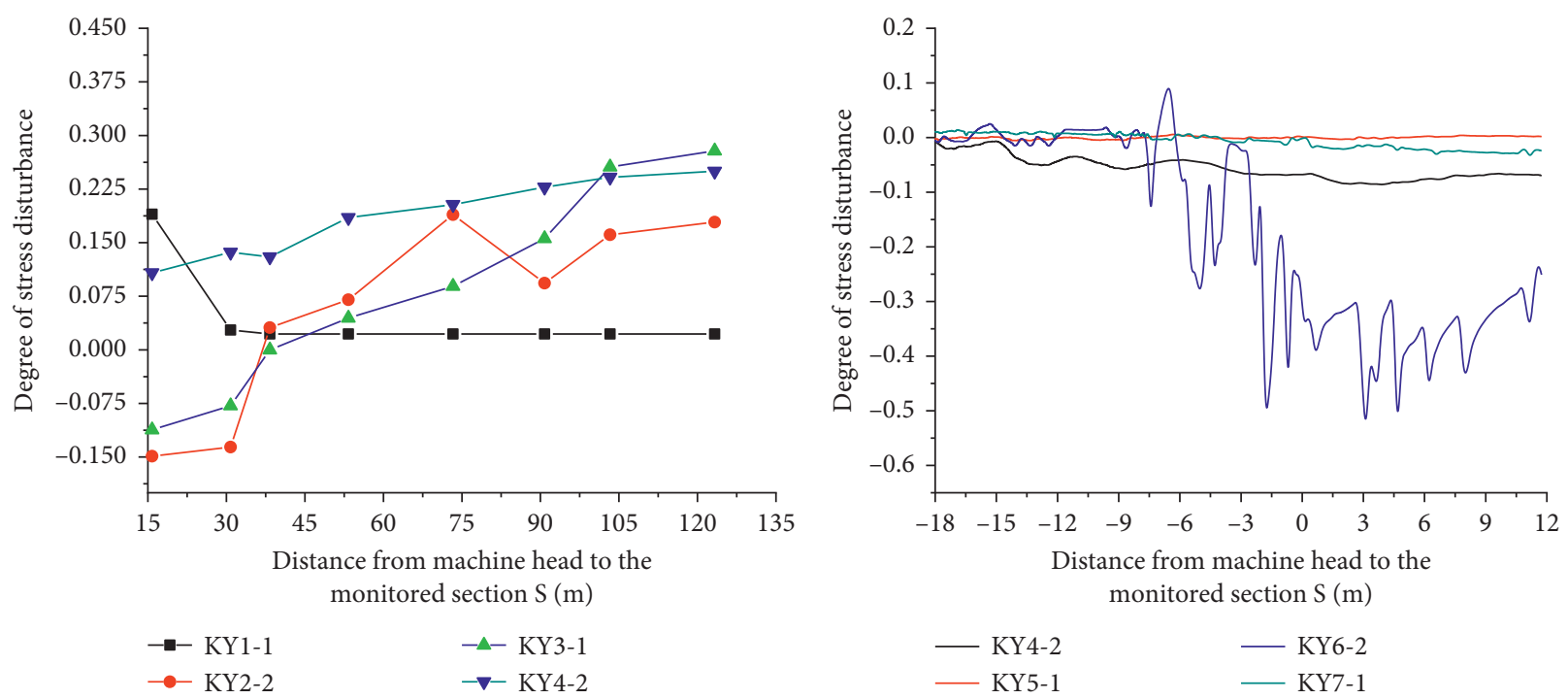

(a)

(b)

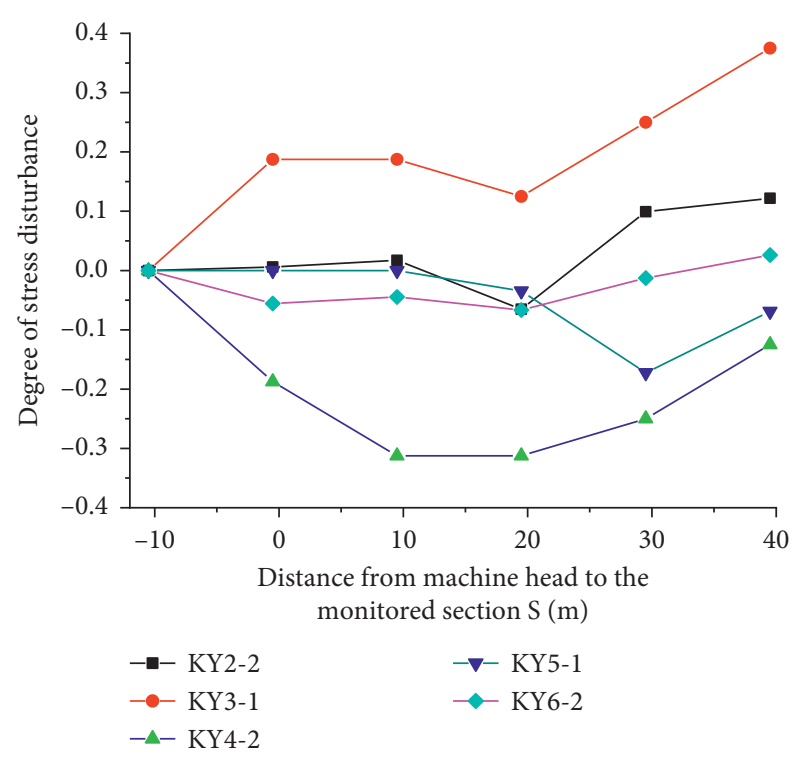

(c)

FIgure 16: Degree of soil disturbance under different lateral spacing. (a) Hole 1 excavates. (b) Hole 3 excavates. (c) Hole 2 excavates. 


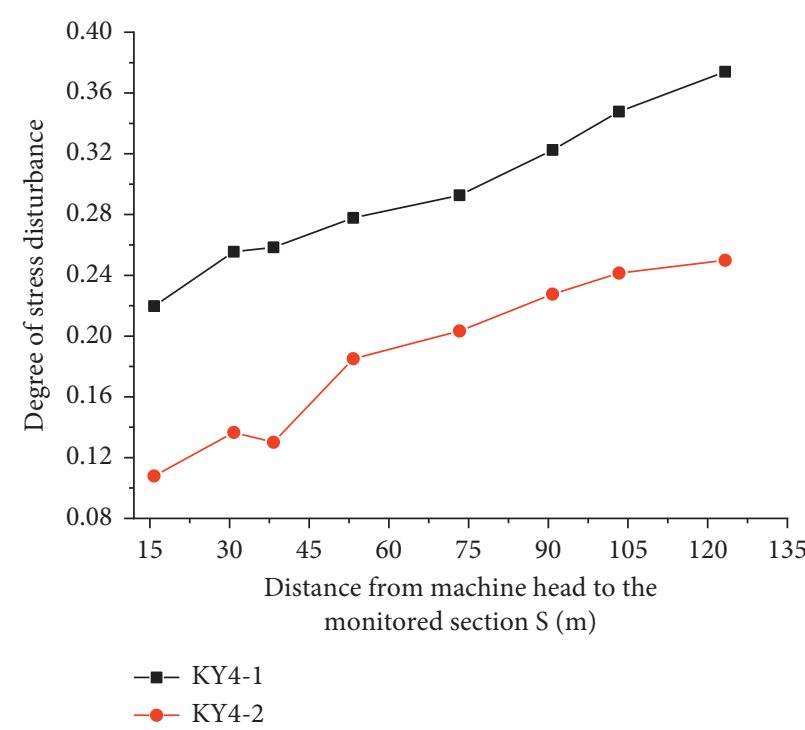

(a)

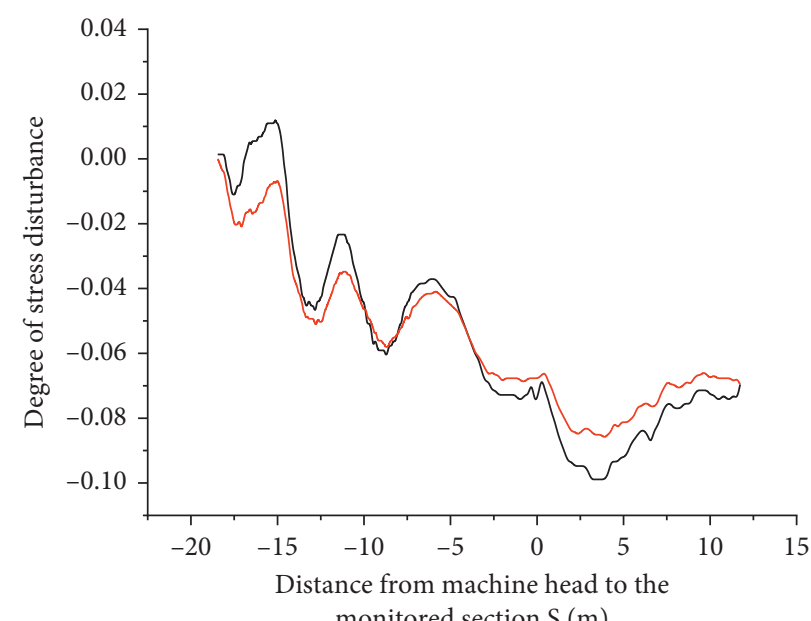

- KY4-1

- KY4-2

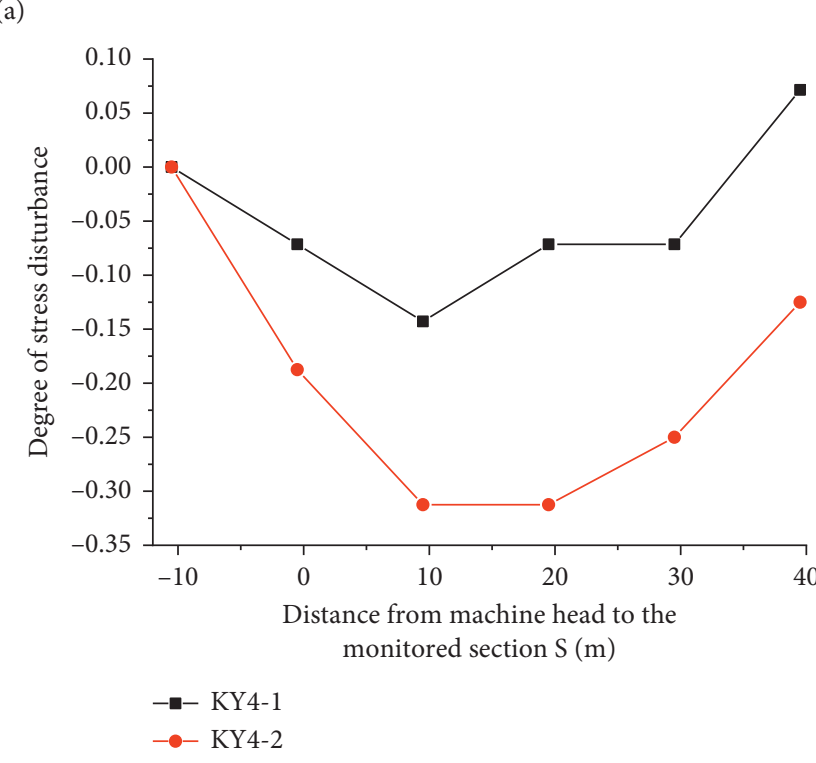

(c)

Figure 17: Degree of soil disturbance under different buried depth. (a) Hole 1 excavates. (b) Hole 3 excavates. (c) Hole 2 excavates. 


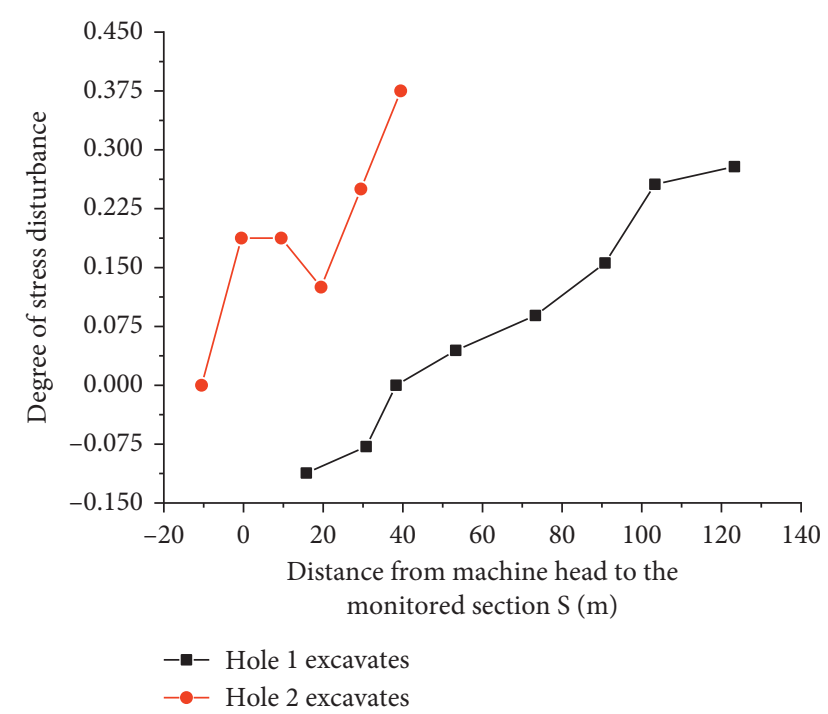

FIgURE 18: Analysis chart of double-hole overlap disturbance degree.

\section{Conclusions}

Combining theory analysis with field test, the effect of soil disturbance in the vertical direction of pipe jacking group and its interaction are mainly discussed in this paper. Based on the actual project, the following conclusions are obtained:

(1) The horizontal jacking of pipe jacking is regarded as the problem of cavity expansion in finite medium in this paper. Based on the cylindrical hole expansion model, the calculation formula of the plastic zone disturbance radius of soil is deduced. Furthermore, according to the limit equilibrium principle, the calculation formula of the transverse disturbance range caused by single-hole jacking construction is established.

(2) The influence of center spacing between two holes and the jacking position on the lateral disturbance range of soil in double-hole and three-hole jacking construction is analyzed and discussed. If the center spacing is large, the soil disturbance only occurs around the plastic disturbance area of each pipe. If the center distance is small, the disturbance superposition will occur. The calculation formulas of the critical value of the center spacing and the lateral overlapping area range in double-hole and threehole jacking are established.

(3) The disturbance superposition mechanism of threehole excavation is the same as that of double-hole excavation, but the influence of jacking position should be considered. When the third hole is located outside the previous two holes, its disturbance superposition effect is the same as that of double-hole excavation. When the third hole is located in the center of the two holes, if the center distance is small, there will be secondary disturbance superposition. The conclusion of theoretical analysis is the same as that of field test, which proves the rationality of theoretical solution effectively.

(4) With the help of the pore water pressure measured in the field test, the disturbance degree of the soil during the multihole jacking is further analyzed. From the analysis results, in the case of single-hole, double-hole, and three-hole jacking, the deeper the buried depth and the closer to the pipe, the greater the soil disturbance. At the same time, affected by the soil structure, the disturbance degree of the soil on the top of the pipe jacking is larger than that on the side, and the disturbance degree of the second hole is larger than that of the first hole, but the degree is not as severe as before.

\section{Data Availability}

The field data in this paper are collected and sorted by field measurement, which is mainly used to verify the theoretical prediction. All data generated or analyzed during this study are included in this article.

\section{Conflicts of Interest}

The authors declare that there are no conflicts of interest regarding the publication of this paper.

\section{Acknowledgments}

The authors acknowledge the financial support provided by the National Natural Science Foundation of China (nos. 51874005 and 51778004) and the Science Research Foundation for Young and Middle-Aged Academic Backbones in Anhui University of Science and Technology.

\section{References}

[1] D. M. Zhang, X. Zong, and H. W. Huang, "Longitudinal deformation of existing tunnel due to underlying shield tunneling," Rock and Soil Mechanics, vol. 35, pp. 2659-2666, 2014.

[2] Y.-F. Chen, H.-K. Zheng, M. Wang, J.-M. Hong, and C.-B. Zhou, "Excavation-induced relaxation effects and hydraulic conductivity variations in the surrounding rocks of a large-scale underground powerhouse cavern system," Tunnelling and Underground Space Technology, vol. 49, pp. 253-267, 2015.

[3] T. Siren, P. Kantia, and M. Rinne, "Considerations and observations of stress-induced and construction-induced excavation damage zone in crystalline rock," International Journal Of Rock Mechanics and Mining Sciences, vol. 73, pp. 165-174, 2015.

[4] Z. Zhang, M. Zhang, and Q. Zhao, "A simplified analysis for deformation behavior of buried pipelines considering disturbance effects of underground excavation in soft clays," Arabian Journal of Geosciences, vol. 8, no. 10, pp. 7771-7785, 2015.

[5] R. Liang, T. Xia, M. Huang, and C. Lin, "Simplified analytical method for evaluating the effects of adjacent excavation on shield tunnel considering the shearing effect," Computers and Geotechnics, vol. 81, pp. 167-187, 2017.

[6] Z. Gang, X. Y. Yang, H. Z. Zhou, Y. M. Du, J. Y. Sun, and X. X. Yu, "A Simplified Prediction method for evaluating 
tunnel displacement induced by laterally adjacent excavations," Computers and Geotechnics, vol. 95, pp. 119-128, 2017.

[7] P. Lueprasert, P. Jongpradist, P. Jongpradist, and S. Suwansawat, "Numerical investigation of tunnel deformation due to adjacent loaded pile and pile-soil-tunnel interaction," Tunnelling and Underground Space Technology, vol. 70, pp. 166-181, 2017.

[8] H. Fu, M. Zhang, F. Wang, T. H. Ling, and X. L. Yang, "The failure mechanism of surrounding rock around an existing shield tunnel induced by an adjacent excavation," Computers and Geotechnics, vol. 117, pp. 103-126, 2020.

[9] B. Liu, D. W. Zhang, S. Y. Liu, and Y. J. Qin, "Numerical simulation and field monitoring on a large cross-section pipejacking underpass traversing existing metro tunnels," Chinese Journal of Rock Mechanics and Engineering, vol. 36, pp. 2850-2860, 2017.

[10] V. K. Dang, D. Dias, N. A. Do, and T. H. Vo, "Impact of blasting at tunnel face on an existing adjacent tunnel," International Journal of Geomate, vol. 15, pp. 22-31, 2018.

[11] Y. H. Fang, H. O. Mo, and C. Y. Zhang, "Theoretical and testing analysis of soild deformation in the area of disturbance caused by pipe jacking," Chinese Journal of Rock Mechanics and Engineering, vol. 22, pp. 601-605, 2003.

[12] G. Wei, R. Q. Xu, and W. Tu, "Testing study and analysis on soil disturbance induced by pipe jacking construction," Chinese Journal of Rock Mechanics and Engineering, vol. 23, pp. 476-482, 2004.

[13] G. Wei, X. J. Wei, and Y. M. Tu, "Analysis on site monitoring of ground deformation induced by paraller pipe jacking construction," Chinese Journal of Rock Mechanics and Engineering, vol. 25, pp. 3299-3304, 2006.

[14] C. L. Li and L. C. Miao, "Determination of the range of shield tunneling-induced soil disturbance," Rock and Soil Mechanics, vol. 37, pp. 759-766, 2016.

[15] B. Chen, S. W. Xu, F. L. Peng, Q. F. Li, and W. M. Ye, "Experimental study of indices for evaluating small disturbance in underground crossing construction," Chinese Journal of Rock Mechanics and Engineering, vol. 30, pp. 2682-2689, 2011.

[16] F.-y. Meng, R.-p. Chen, and X. Kang, "Effects of tunnelinginduced soil disturbance on the post-construction settlement in structured soft soils," Tunnelling and Underground Space Technology, vol. 80, pp. 53-63, 2018.

[17] Y. Xu, D. a. Sun, J. Sun, D. Fu, and P. Dong, "Soil disturbance of Shanghai silty clay during EPB tunnelling," Tunnelling and Underground Space Technology, vol. 18, no. 5, pp. 537-545, 2003.

[18] T. Lu, S. Liu, G. Cai, K. Wu, and W. Xia, "Investigation of soft soil disturbance and recompression settlement induced by excavation," Rock and Soil Mechanics, vol. 41, 2021.

[19] H. N. Feng, X. G. Wen, G. Wei, C. Liu, Z. X. Yang, and X. N. Gong, "In-situ test research on influence of pipe jacking on soil," Rock and Soil Mechanics, vol. 24, pp. 781-785, 2003.

[20] Y. Zheng, W. Q. Ding, and L. S. Chen, "Study of measured data and soil disturbance influenced by pipe Jacking Construction," Chinese Journal Of Underground Space And Engineering, vol. 6, pp. 1015-1020, 2010.

[21] J. Guo, B. S. Ma, Y. S. Zhao, X. H. Chen, and H. X. Ji, "Soil disturbance measurement and analysis of large section rectangular pipe-jacking construction," Special Structure, vol. 36, pp. 1-7, 2019.

[22] P. Zhang, B. S. Ma, C. Zen, and X. Y. Wang, "Site monitoring analysis of contact pressure during steel curved pipe jacking with larger buried depth," Journal of Huazhong University Of
Science and Technology (natural Science Edition), vol. 44, pp. 93-97, 2016.

[23] W. Zhao, B. F. Jiang, P. J. Jia, J. C. Dong, and Y. Zhao, "Theoretical analysis on soil disturbance induced by densely packed circular pipes with Fringes," Chinese Journal of Underground Space and Engineering, vol. 15, pp. 1734-1740, 2019.

[24] A. S. Vesic, "Expansion of cavities in infinite soil mass," in Proceedings of the ASCE, Vancouver, Canada, July 1972.

[25] H. S. Yu, Cavity Expansion Methods in Geomechanics, Kluwer Academic Publishers, Amsterdam, Netherlands, 2000.

[26] X.-L. Yang and J.-F. Zou, "Cavity expansion analysis with non-linear failure criterion," Proceedings of the Institution of Civil Engineers-Geotechnical Engineering, vol. 164, no. 1, pp. 41-49, 2011.

[27] S. L. Chen and Y. N. Abousleiman, "Exact drained solution for cylindrical cavity expansion in modified Cam Clay soil," Geotechnique, vol. 63, pp. 510-517, 2013.

[28] S. H. Jia, C. F. Zhao, and C. Zhao, "Analysis of expanded radius and internal expanding pressure of cylindrical hole," Chinese Journal of Rock Mechanics and Engineering, vol. 34, pp. 182-188, 2015

[29] W. J. Han, S. Y. Liu, D. W. Zhang, and C. Y. Gu, "Numerical simulation of pressure-controlled cavity expansion," Rock and Soil Mechanics, vol. 31, pp. 405-411, 2010.

[30] A. Hedayat and J. Weems, "The elasto-plastic response of deep tunnels with damaged zone and gravity effects," Rock Mechanics and Rock Engineering, vol. 52, no. 12, pp. 5123-5135, 2019.

[31] Y. Xiang and S. Feng, "Theoretical prediction of the potential plastic zone of shallow tunneling in vicinity of pile foundation in soils," Tunnelling and Underground Space Technology, vol. 38, pp. 115-121, 2013.

[32] B. Azari, B. Fatahi, and H. Khabbaz, "Assessment of the elastic-viscoplastic behavior of soft soils improved with vertical drains capturing reduced shear strength of a disturbed zone," International Journal of Geomechanics, vol. 16, pp. 4001-4011, 2016.

[33] C.-F. Tsang, F. Bernier, and C. Davies, "Geohydromechanical processes in the Excavation Damaged Zone in crystalline rock, rock salt, and indurated and plastic clays-in the context of radioactive waste disposal," International Journal of Rock Mechanics and Mining Sciences, vol. 42, no. 1, pp. 109-125, 2005.

[34] J. M. Kranabetter, S. Haeussler, and C. Wood, "Vulnerability of boreal indicators (ground-dwelling beetles, understory plants and ectomycorrhizal fungi) to severe forest soil disturbance," Forest Ecology and Management, vol. 402, pp. 213-222, 2017.

[35] D. J. Yuan, F. Yin, H. W. Wang, Q. F. Huang, and H. Xiao, "Study of soil disturbance caused by super-large diameter slurry shield tunneling," Chinese Journal of Rock Mechanics and Engineering, vol. 28, pp. 2074-2080, 2009. 